\title{
Orai1 promotes tumor progression by enhancing cancer stemness via NFAT signaling in oral/oropharyngeal squamous cell carcinoma
}

\author{
Sung Hee Lee $^{1}$, Nicole Kristina Rigas ${ }^{1}$, Chang-Ryul Lee ${ }^{1}$, April Bang ${ }^{1}$, Sonal \\ Srikanth ${ }^{2}$, Yousang Gwack ${ }^{2}$, Mo K. Kang ${ }^{1,3}$, Reuben H. Kim ${ }^{1,3}$, No-Hee Park ${ }^{1,3,4}$ and \\ Ki-Hyuk Shin ${ }^{1,3}$ \\ ${ }^{1}$ The Shapiro Family Laboratory of Viral Oncology and Aging Research, UCLA School of Dentistry, Los Angeles, CA, USA \\ 2 Department of Physiology, David Geffen School of Medicine at UCLA, Los Angeles, CA, USA \\ ${ }^{3}$ UCLA Jonsson Comprehensive Cancer Center, Los Angeles, CA, USA \\ ${ }^{4}$ Department of Medicine, David Geffen School of Medicine at UCLA, Los Angeles, CA, USA \\ Correspondence to: Ki-Hyuk Shin, email: kshin@dentistry.ucla.edu
}

Keywords: Orail, OSCC, cancer stem cells, NFAT, SOCE

Received: May 20, $2016 \quad$ Accepted: May 26, $2016 \quad$ Published: June 01, 2016

\section{ABSTRACT}

Emerging evidence indicates that Orai1, a key calcium channel for store-operated $\mathrm{Ca}^{2+}$ entry, is associated with human cancer. However, the underlying mechanism by which Orai1 regulates cancer progression remains unknown. Here we report that intracellular level of Orai1 is increased in a stepwise manner during oral/ oropharyngeal carcinogenesis and highly expressed in cancer stem-like cell (CSC)enriched populations of human oral/oropharyngeal squamous cell carcinoma (OSCC). Ectopic Orai1 expression converted non-tumorigenic immortalized oral epithelial cells to malignant cells that showed CSC properties, e.g., self-renewal capacity, increased ALDH1 ${ }^{\text {HIGH }}$ cell population, increased key stemness transcription factors, and enhanced mobility. Conversely, inhibition of Orai1 suppressed tumorigenicity and CSC phenotype of OSCC, indicating that Orai 1 could be an important element for tumorigenicity and stemness of OSCC. Mechanistically, Orai1 activates its major downstream effector molecule, NFATc3. Knockdown of NFATc3 in the Orai1-overexpressing oral epithelial cells abrogates the effect of Orai 1 on CSC phenotype. Moreover, antagonist of NFAT signaling also decreases CSC phenotype, implying the functional importance of Orai1/ NFAT axis in OSCC CSC regulation. Our study identifies Orai1 as a novel molecular determinant for OSCC progression by enhancing cancer stemness, suggesting that inhibition of Orai1 signaling may offer an effective therapeutic modality against OSCC.

\section{INTRODUCTION}

OSCC is the sixth most common cancer and an important public health concern worldwide [1]. Risk factors for OSCC development in the elderly are typically associated with a life-long history of cigarette smoking and heavy alcohol consumption [2,3]. OSCC is often preceded by clinically well-defined lesions, such as leukoplakia that is histologically classified as dysplastic or non-dysplastic leukoplakia. Dysplastic leukoplakia is defined as oral premalignant lesion and associated with a likely progression to cancer; however, it is not an accurate predictor of cancer risk $[4,5]$. Early stage tumors can usually be managed through surgery and radiotherapy. However, successful treatment is inversely proportional to the extent of the disease at the time of treatment. A combination of chemotherapy and radiation therapy, although effective in treating $97 \%$ of early stage tumors, was only $33 \%$ effective in treating advanced tumors [6]. In fact, the clinical stage at which the diagnosis is made is the most important prognostic indicator of oral cancer. Clearly, identifying the biomarker that allows detection of early stage cellular aberration leading to OSCC tumorigenesis is critically important for reducing 
of cancer-associated morbidity.

Recent studies have unveiled and validated the pathophysiologic role of CSCs (alternatively cancer initiating cells) in long-term sustenance of cancers [7]. CSCs are small subpopulations of tumor cells with self-renewal capacity and share many molecular similarities to embryonic and normal adult stem cells. CSCs have been isolated from various primary tumors and established cancer cell lines, including OSCC $[8,9]$. They are also potentially responsible for drug resistance, metastasis, and recurrence of cancers. Therefore, CSCs drive the perpetuity of the disease while producing cellular heterogeneity of cancer tissues, making them strategically plausible targets for cancer therapies. The phenotypes of CSC have been reported to be maintained by several endogenous signaling pathways, such as Notch, Hedgehog, and Wnt [10, 11], which are frequently activated in human cancers [11-13]. In addition, increasing numbers of publications reported that CSCs could be epigenetically regulated by microRNAs $[14,15]$. Therefore, advancing our understanding of the molecular properties and signaling pathways unique to OSCC CSCs is crucial for developing a new generation of targeted and effective therapies for oral/oropharyngeal cancer.

Calcium $\left(\mathrm{Ca}^{2+}\right)$ plays indispensable roles in cell signaling pathways that involved in maintaining and regulating in normal biological processes [16-18]. $\mathrm{Ca}^{2+}$ homeostasis is disrupted during carcinogenesis, thereby leading to deregulated cell proliferation, migration and suppression of apoptosis [19-22]. In most of non-excitable cells, $\mathrm{Ca}^{2+}$ influx is tightly regulated by the store-operated $\mathrm{Ca}^{2+}$ entry (SOCE) pathway and mediated through storeoperated $\mathrm{Ca}^{2+}$ release-activated $\mathrm{Ca}^{2+}$ (CRAC) channels [23]. Orail is an essential pore-subunit of the CRAC channels [24-26]. Upon stimulation, the cells release $\mathrm{Ca}^{2+}$ from the endoplasmic reticulum (ER) followed by extracellular $\mathrm{Ca}^{2+}$ influx through SOCE. SOCE not only refills the depleted ER $\mathrm{Ca}^{2+}$ stores but also provides a direct $\mathrm{Ca}^{2+}$ signal to activate downstream responses including the nuclear factor of activated T cells (NFAT) signaling pathway $[27,28]$. Orail has been extensively studied in immunology as NFAT is the transcription factor that is necessary for activation, differentiation, and effector functions of T cells [29].

Currently, emerging evidence has indicated the efficacy of targeting Orai1 to inhibit cancer growth and metastasis [30-34]. Orai1 was overexpressed in various human cancers, including lung, esophagus, brain, and kidney [33-35]. Clinically, Orail overexpression strongly linked to poor overall and recurrence-free survival in human esophageal SCC [36, 37] and non-small cell lung cancer [35]. Orail promoted cancer cell migration/ invasion [30], drug resistance [38] and angiogenesis $[39,40]$, three phenotypes of which are well known for CSC characteristics [7, 41, 42]. However, a considerable knowledge gap remains in our understanding of the role of Orai1 in oral/oropharyngeal carcinogenesis and in the regulation of CSCs.

In the present study, we report for the first time that Orail expression is elevated in a stepwise manner in oral/oropharyngeal carcinogenesis and enriched in OSCC CSC populations. We further provided evidence that Orail promotes OSCC progression by enhancing cancer stemness via NFAT signaling, suggesting a novel CSC regulatory mechanism by Orail/NFAT axis.

\section{RESULTS}

\section{Orai1 is overexpressed in oral/oropharyngeal carcinogenesis}

To investigate the role of Orail in oral/ oropharyngeal carcinogenesis, we first determined the expression level of Orail protein in normal human oral keratinocytes (NHOK), non-tumorigenic immortalized oral epithelial cell lines (NOK-SI, OKF6/tert, and HOK16B), and OSCC cell lines (HOK-16B-BapT, SCC4, SCC15, SCC1, SNU1041, YD9, YD15M, UM17B, SNU1076 and SCC9/TNF) by western blot analysis. All of the OSCC cell lines expressed higher level of Orail protein compared to the tested immoralized cell lines (Figure 1A). All immoralized cell lines showed higher expression of Orail protein compared to NHOK (Figure 1A). Our findings suggested a stepwise increase of Orai1 expression during oral/oropharyngeal carcinogenesis. To extend our findings, immunohistochemical (IHC) staining for Orail was performed using normal human oral epithelia (NHOE), oral dysplasia, and OSCC tissues. The results of in vivo Orail staining are summarized in Figure 1B, and a typical Orail staining observation in NHOE, dysplasia and OSCC tissue is shown in Figure 1C. In $13 \mathrm{NHOE}$, weak Orail staining was detected in 11 cases $(84.6 \%)$, and moderate staining detected in 2 cases (15.4\%). Of 15 dysplastic tissues, weak staining was detected in 2 cases $(13.3 \%)$, moderate staining detected in 8 cases $(53.3 \%)$, and strong staining detected in 5 cases $(33.3 \%)$. In 19 OSCC samples, 16 cases $(84.2 \%)$ demonstrated strong staining and 3 cases $(15.8 \%)$ with very strong staining. Mean IHC scores for Orail in NHOE, dysplasia, and OSCC were 1.15, 2.2, and 3.16, respectively, showing statistical significant difference $(P<$ 0.0001 between NHOE and dysplasia; $P<0.0001$ between dysplasia and OSCC). Orail was present predominantly in the plasma membrane, with diffused staining in both the cytoplasm and nucleus (Figure 1C). Using laser capture microdissection (LCM), we determined the level of Orai1 mRNA in dysplasia and OSCC tissues and found that Orail mRNA is also increased in OSCC compared to dysplastic tissues (Supplementary Figure 1). Taken together, our findings clearly indicate a stepwise elevation 


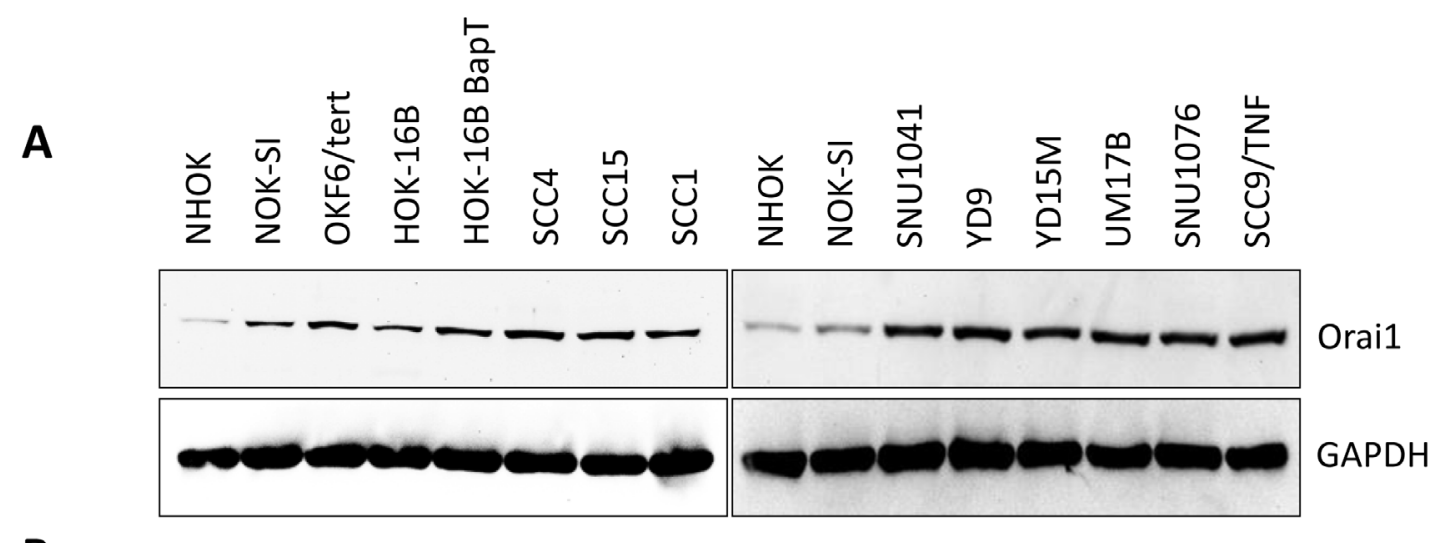

B

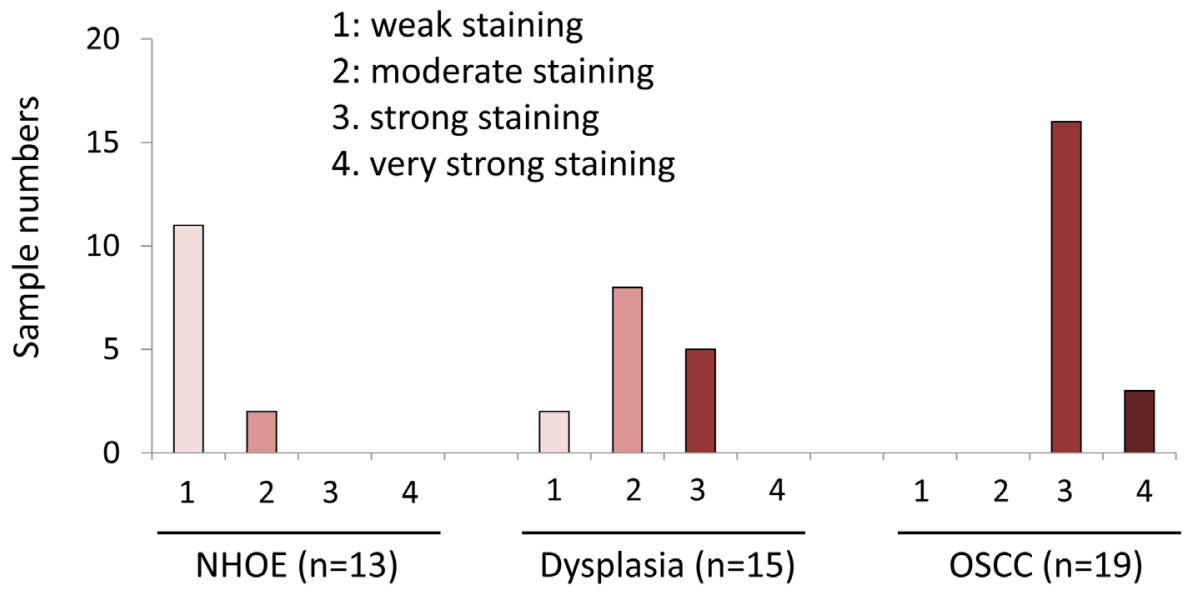

C
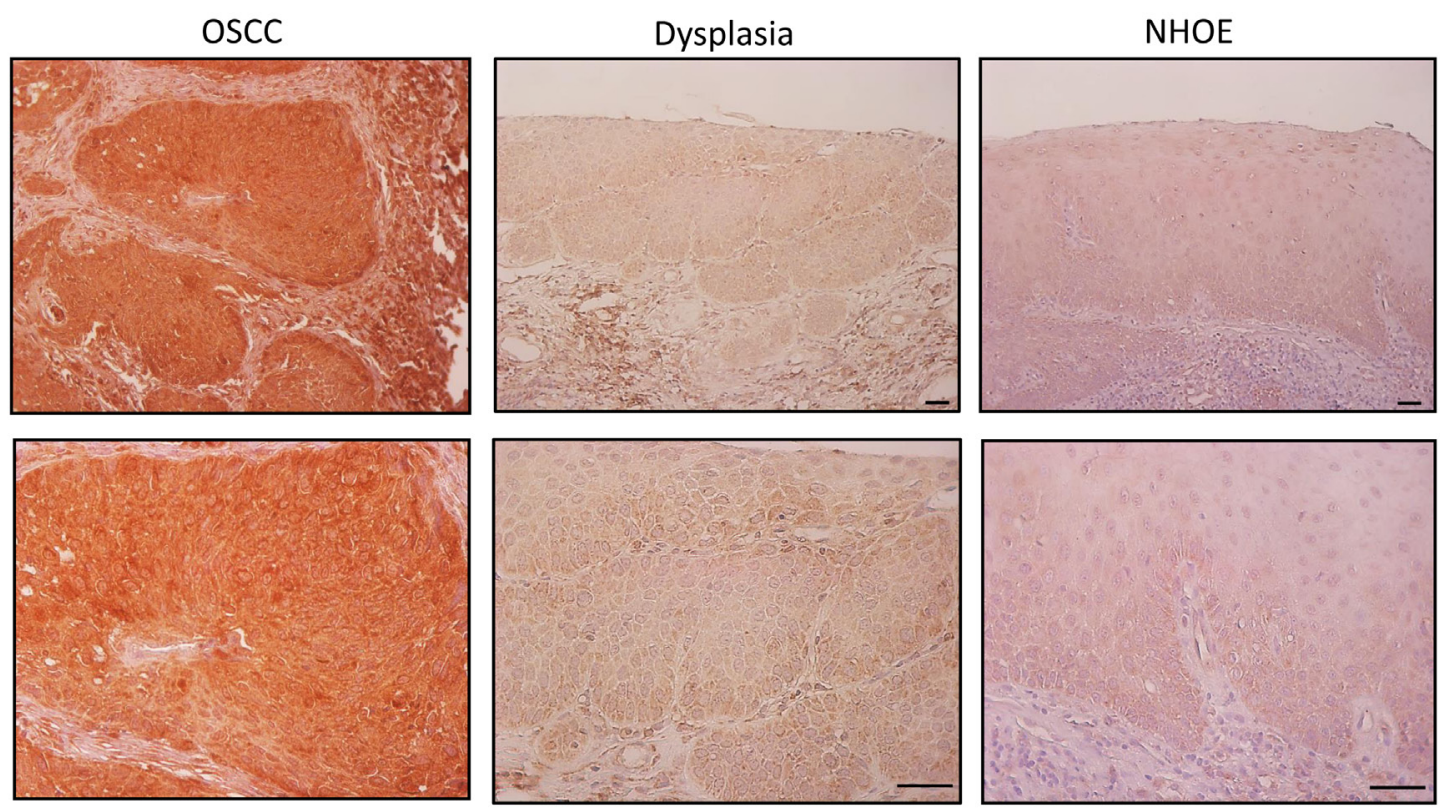

Figure 1: A stepwise increase of Orai1 in oral/oropharyngeal carcinogenesis. A. Level of Orai1 protein was determined in normal human oral keratinocyte (NHOK), 3 precancerous, non-tumorigenic immortalized oral epithelial cell lines (NOK-SI, OKF6/tert, and HOK-16B) and 10 OSCC cell lines (HOK-16B-BapT, SCC4, SCC9/TNF, UM17b, and YD38) by performing Western blot. GAPDH was used as a loading control. B. In vivo Orail expression was determined in normal human oral epithelia (NHOE), oral dysplasia and OSCC tissues by immunohistochemical staining. C. Representative examples of Orail immunohistochemical staining in NHOE, oral dysplasia and OSCC tissues in vivo. Bar indicates $100 \mu \mathrm{m}$. 
of Orail protein during oral/oropharyngeal carcinogenesis, suggesting an important role of Orail in the progression of OSCC.

\section{Orai1 is required for tumorigenicity of OSCC}

Many studies reported the efficacy of targeting Orailto suppress cancer growth [30-34]. A point mutation in the negatively charged residues of Orail is known to function as a dominant negative mutant [26]. To investigate the role of Orail in OSCC growth, we inhibited Orail using a dominant negative Orail mutant (E106Q). SCC4, a human tongue squamous carcinoma cell line, was infected with retroviral vector expressing E106Q or empty vector (EV) as a control. As shown in Figure $2 \mathrm{~A}$, treatment of SCC4/EV with $1 \mu \mathrm{M}$ thapsigargin (TG), an ER $\mathrm{Ca}^{2+}$-ATPase inhibitor, resulted in a rapid rise in intracellular $\mathrm{Ca}^{2+}$ level, consistent with depletion of $\mathrm{ER} \mathrm{Ca}^{2+}$ stores. Subsequent addition of $\mathrm{Ca}^{2+}$ to the extracellular bath solution triggered another increase in the $\mathrm{Ca}^{2+}$ level, consistent with $\mathrm{Ca}^{2+}$ influx from the extracellular solution. However, SCC4/E106Q failed to show the increase in $\mathrm{Ca}^{2+}$ influx. Our finding indicated that E106Q successfully impaired Orail-mediated SOCE in OSCC cells, confirming the inactivation of Orail (Figure 2A). E106Q slightly lowered proliferation capacity of SCC4 (Figure 2B).
A

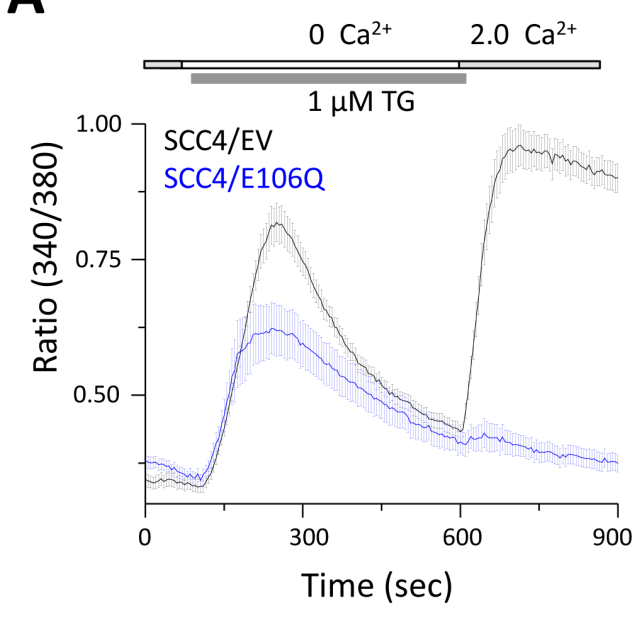

C

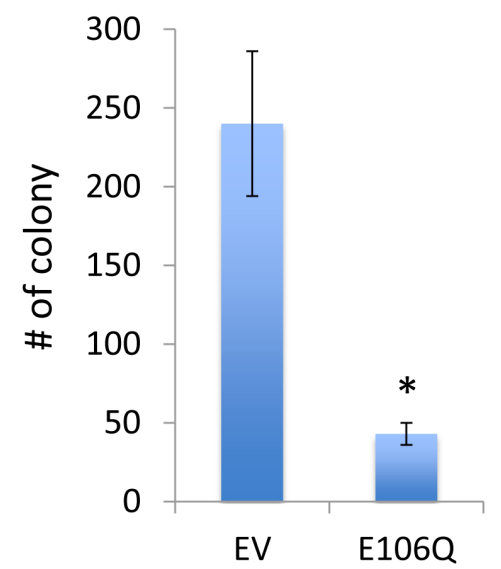

B

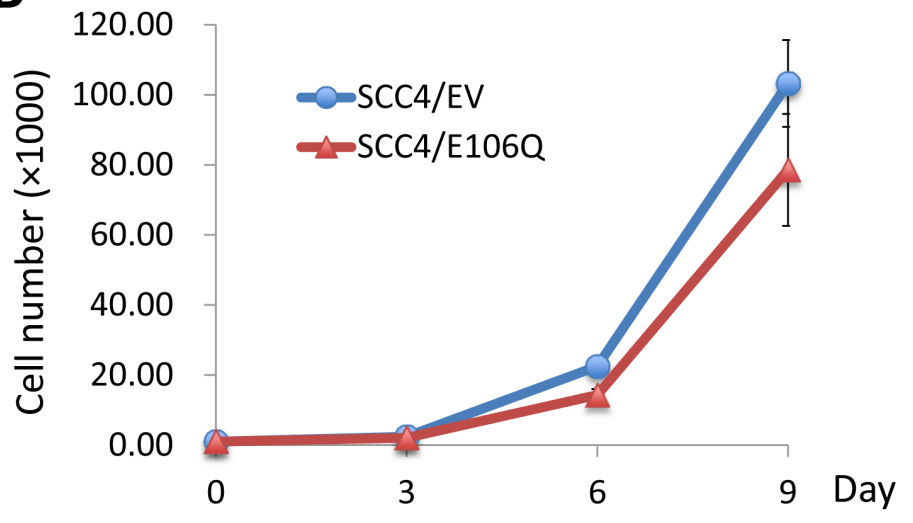

D

\begin{tabular}{|l|c|}
\hline Group & In vivo tumorigenicity \\
\hline SCC4/EV & $3 / 5$ \\
\hline SCC4/E106Q & $0 / 5$ \\
\hline
\end{tabular}

SCC4/E106Q

SCC4/EV

Figure 2: The dominant negative Orai1 mutant (E106Q) suppresses tumorigenicity of OSCC in vivo. A. SCC4 cells were infected with retroviruses containing E106Q or empty vector (EV) as a control. Intracellular $\mathrm{Ca}^{2+}$ imaging assay was performed to confirm the inactivation of Orail function. Intracellular $\mathrm{Ca}^{2+}$ stores were depleted with $1 \mu \mathrm{M}$ TG in the absence of extracellular $\mathrm{Ca}^{2+}$, followed by re-addition of $2 \mathrm{mM} \mathrm{Ca}^{2+}$. $\mathrm{Ca}^{2+}$ influx was analyzed by single-cell video imaging of Fura2-labeled, GFP+ cells. More than $30 \mathrm{GFP}+$ cells were analyzed in each experiment. B. Effect of E106Q on cell proliferation of SCC4 was determined by cell counting. Data are means \pm SD of triplicate experiments. C. Effect of E106Q on anchorage independent growth of SCC4 was determined by soft agar assay. Data are means \pm SD of triplicate experiments. ${ }^{*} P<0.001$ by two-tailed Student's $t$ test. D. Effect of E106Q on in vivo tumorigenicity of SCC4 was determined by xenograft tumor assay. SCC4/EV and SCC4/E106Q were injected subcutaneously into five nude mice. Mice were killed at week 6 , and tumors were surgically removed from all animals and photographed. 
Effect of Orail inactivation on tumorigenic potential of OSCC was then evaluated using in vitro anchorage independent growth and in vivo tumor xenograft assay. E106Q significantly reduced formation of colonies in soft agar suggesting decreased anchorage independent growth ability by Orail inactivation (Figure 2C). As demonstrated by xenograft tumor assay in nude mice, 3 out of 5 animals inoculated with SCC4/EV formed tumors, whereas the animals inoculated with SCC4/E106Q failed to form tumor in vivo (Figure 2D). These findings indicate that Orail is required for tumorigenicity of OSCC.

\section{Orai1 is required for the maintenance of CSC phenotype and increased in CSC-enriched population}

A key feature of CSCs is self-renewal capacity, which appears to be a driving force for the initiation and maintenance of tumorigenicity [41]. Our data revealed the crucial role of Orail function in tumorigenicity of OSCC. To determine the role of Orail on CSC phenotype of OSCC, we first employed tumor sphere formation assay in which CSCs can be enriched in non-adherent tumor spheres [43]. Thus, abundance and the growth kinetics of tumor spheres are indicative of CSC content and selfrenewal capacity in a given culture of heterogeneous cancer cells. We determined the effect of E106Q on selfrenewal capacity of two OSCC cell lines, SCC4 and HOK16B BapT. Tumor sphere formation assay revealed that E106Q significantly inhibits the tumor sphere forming ability of both cell lines (Figure $3 \mathrm{~A}$ and $3 \mathrm{~B}$ ), indicating that Orail is indeed essential for sustaining self-renewal capacity of CSCs. ALDH1 activity is one of CSC markers and known to enrich CSCs in solid malignancies, including head and neck cancer [44]. Thus, we investigated whether Orai1 inhibition could affect CSC property by performing ALDH1 assay. The assay revealed a significant decrease in ALDH1 activity in SCC4/E106Q compared to their control SCC4/EV (Figure 3C). Because another wellknown property of CSCs is their metastatic potential [41], we examined the effect of Orailinhibiton on metastatic potential of OSCC in vitro. As demonstrated by a transwell migration assay (Figure 3D), E106Q markedly suppressed migration of SCC4 cells. We also found a significant inhibitory effect of E106Q on invasion ability using Matrigel invasion assay (Figure 3E). This is consistent observation reported by other $[30,45]$. To extend these observations, we determined whether a chemical inhibitor of Orail also suppresses CSC phenotype. We treated OSCC cells with the Orail-specific small molecular blocker, compound 5D [46] and found that the Orai1 inhibitor dramatically inhibited tumor sphere forming ability (Figure 3F) and migration (Figure 3G) at the dose of $15 \mu \mathrm{M}$. We observed no significant effect of compound $5 \mathrm{D}$ on cell proliferation at the same dose (data not shown), indicating that the inhibitory effect of compound 5D on CSC phenotype was unlikely an artifact of slower cell proliferation and a cytotoxic effect of the chemical. Similar to the effects of E106Q and compound 5D on CSC phenotype, Orai1 knockdown reduced self-renewal and migration ability of SCC4 (Supplementary Figure 2).

To further examine the importance of Orail in CSC, we compared Orail expression of CSC-enriched populations with that of non-CSC populations. Orai1 expression is highly enriched in tumor spheres compared with their corresponding adherent monolayer cells (Figure 4A and 4B). Similarly, stemness transcription factors, Nanog, Oct4, KLF4, Lin28, and Sox2 were enriched in tumor spheres (Figure 4A). We also observed robust induction of CSC marker, ALDH1, in tumor spheres (Figure 4A), confirming that tumor spheres are CSCenriched cell population. Furthermore, we sorted the ALDH $1^{\mathrm{HIGH}}$ and ALDH1 ${ }^{\text {LOW }}$ cell populations from SCC4 according to ALDH1 activity (Figure 4C) and examined Orail expression in these two cell populations. The ALDH1 $1^{\mathrm{HIGH}}$ population expressed higher Orail protein than the ALDH1 ${ }^{\text {LOW }}$ population (Figure 4D). Overall, our data clearly indicate that Orail is enriched in CSC and essential for maintenance of CSC phenotype in OSCC.

\section{Orai1 endows non-tumorigenic oral epithelial cells with tumorigenic potential and CSC phenotype}

Having established that increased Orail is associated with OSCC progression and is necessary for CSC phenotype, we next examined whether ectopic Orai1 expression confers tumorigenic capacity and CSC phenotype on non-tumorigenic immortalized oral epithelial cells. As shown in Figure 5A, we overexpressed Orai1 in non-tumorigenic immortalized oral epithelial cells, HOK-16B, using the lentiviral vector expressing Orai1 or empty vector (EV) as a control. We first examined the effect of Orail on cell proliferation and found that Orail overexpression led to robust increase in proliferation capacity of $\mathrm{HOK}-16 \mathrm{~B}$ in vitro (Figure 5B). To further examine the effect of Orail on tumor growth in vivo, we injected the cells into nude mice and observed tumor formation. Three out of 5 mice injected with HOK16B/Orail developed tumor, whereas, as expected, the mice injected with $\mathrm{HOK}-16 \mathrm{~B} / \mathrm{EV}$ failed to form tumor (Figure 5C). Histological examination of tumors grown in mice injected with HOK-16B/Orail revealed the presence of malignant cells, with hyperchromatic nuclei, prominent nucleoli, and active mitosis (Figure 5D), indicating that Orail conferred tumorigenicity to the non-tumorigenic cells.

Next, we investigated the effect of Orail on CSC phenotype in HOK-16B. Ectopic Orail expression resulted in robust induction in tumor sphere formation, indicating the acquisition of self-renewal capacity by 
A

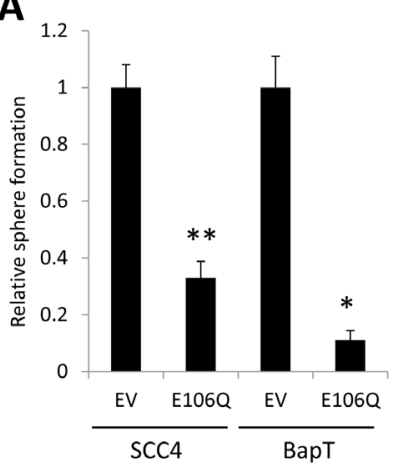

B

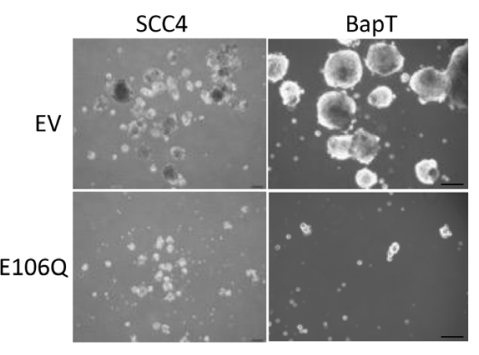

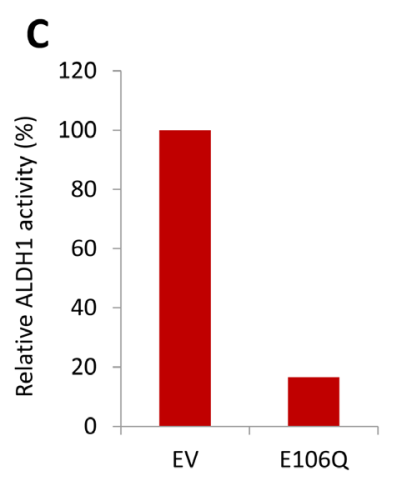

$\mathbf{F}$

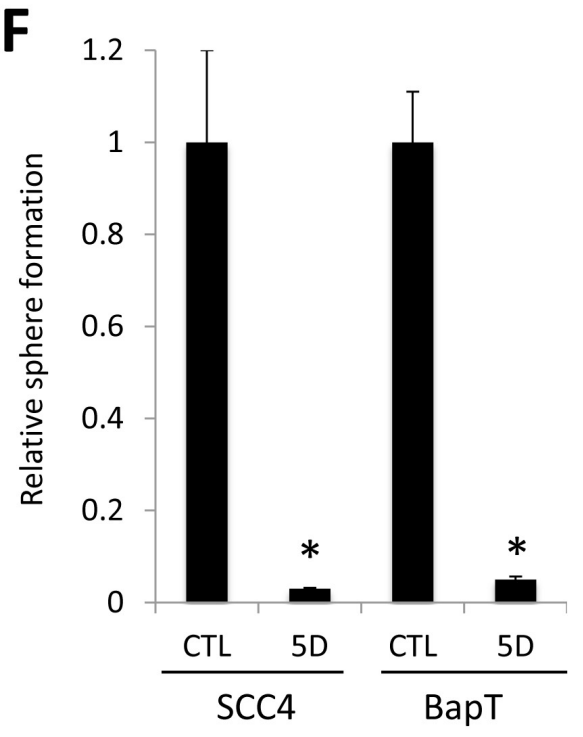

D 500

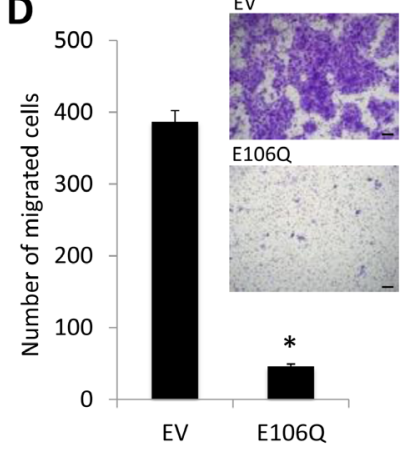

$\mathbf{G}$
E

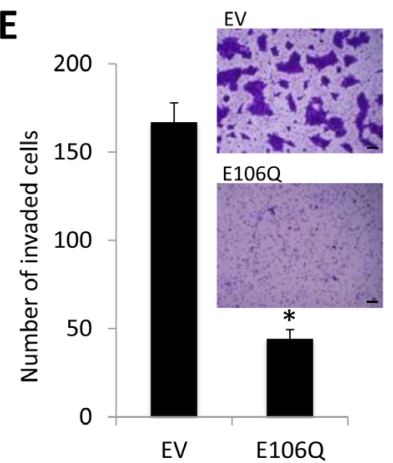

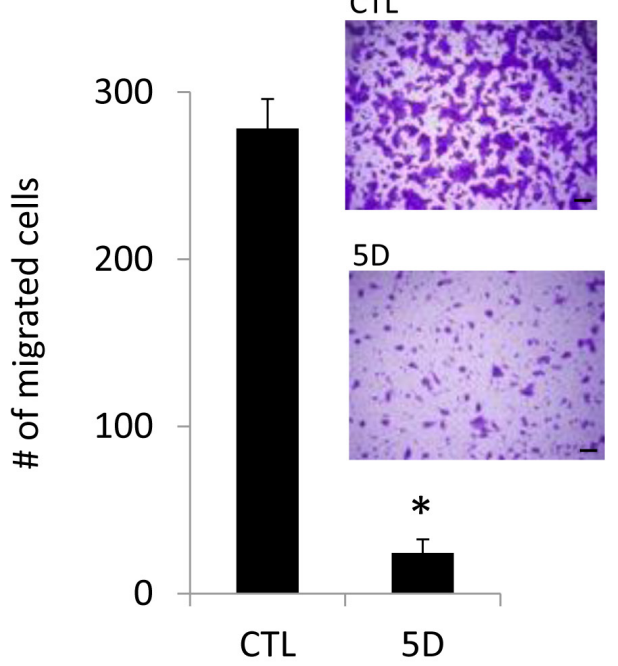

Figure 3: The dominant negative Orai1 mutant (E106Q) inhibits CSC phenotype. A. Effect of E106Q on self-renewal capacity of two OSCC cell lines, SCC4 and HOK-16B BapT, was determined by tumor sphere formation assay. Data are means \pm SD of triplicate experiments. ${ }^{*} P<0.01$ and $* * P<0.05$ by two-tailed Student's $t$ test. B. Representative images of tumor spheres formed by E106Q-transduced OSCC cell lines (SCC4/E106Q and BapT/E106Q) and their corresponding controls (SCC4/EV and BapT/EV). Bar indicates $100 \mu \mathrm{m}$. C. Effect of E106Q on ALDH1 activity in SCC4 was determined by Aldefluor assay. D. Effect of E106Q on migration ability in SCC4 was determined by transwell migration assay. Migration ability was described as number of migrated cells per field with data as mean $\pm \mathrm{SD}$ for 3 randomly selected fields. ${ }^{*} P<0.01$ by two-tailed Student's $t$ test. Representative images of transwell migration assay are shown on the right. Bar indicates $100 \mu \mathrm{m}$. E. Effect of E106Q on invasion ability of SCC4 was determined by Matrigel invasion assay. Invasion ability was described as the number of invaded cells per field with the data as mean $\pm \mathrm{SD}$ for 3 randomly selected fields. ${ }^{*} P$ $<0.01$ by two-tailed Student's $t$ test. Representative images of Matrigel invasion assay are shown on the right. F. Effect of Orail-specific chemical blocker, compound 5D, on self-renewal capacity of two OSCC cell lines, SCC4 and HOK-16B BapT, was determined by tumor sphere formation assay. $* P<0.01$ by two-tailed Student's $t$ test. G. Effect of compound $5 \mathrm{D}$ on migration ability in SCC4 was determined by transwell migration assay. ${ }^{*} P<0.01$ by two-tailed Student's $t$ test. Representative images of transwell migration assay are shown on the right. 
Orail (Figure 6A). The flow analysis revealed a significant increase in ALDH1+ cell population in HOK-16B/Orai1 compared to HOK-16B/EV (13.1\% vs. 1.4\%; Figure 6B). As demonstrated by a transwell migration assay (Figure 6C), HOK-16B/Orail migrated significantly faster than HOK-16B/EV. The effect of Orail on CSC phenotype was further validated by qPCR analysis of stemness transcription factors and CSC-related genes (Figure 6D). Orail increased stemness transcription factors (i.e., Nanog, Oct4, Sox2, KLF4, and Myc) and CSC-related genes (i.e., Ezh2, Gli1, Hes1, Zeb2, FGF4, and IL4). Our findings indicate that Orail indeed conferred CSC phenotype on the non-tumorigenic oral epithelial cells.

\section{NFAT signaling is indispensable for Orai1- induced CSC phenotype}

It is well documented that Orail-mediated SOCE activates downstream responses including NFAT signaling pathway [27, 28]. Emerging evidence has suggested that NFAT signaling plays an important role in tumorigenesis [47]. Thus, we investigated whether Orail promotes CSC phenotype through NFAT signaling pathway. We treated HOK-16B/Orail with the NFAT antagonist, cyclosporine A (CsA) [48], and subsequently performed the assays for CSC properties. The NFAT inhibitor significantly inhibited self-renewal (Figure 7A) and migration (Figure 7B) of
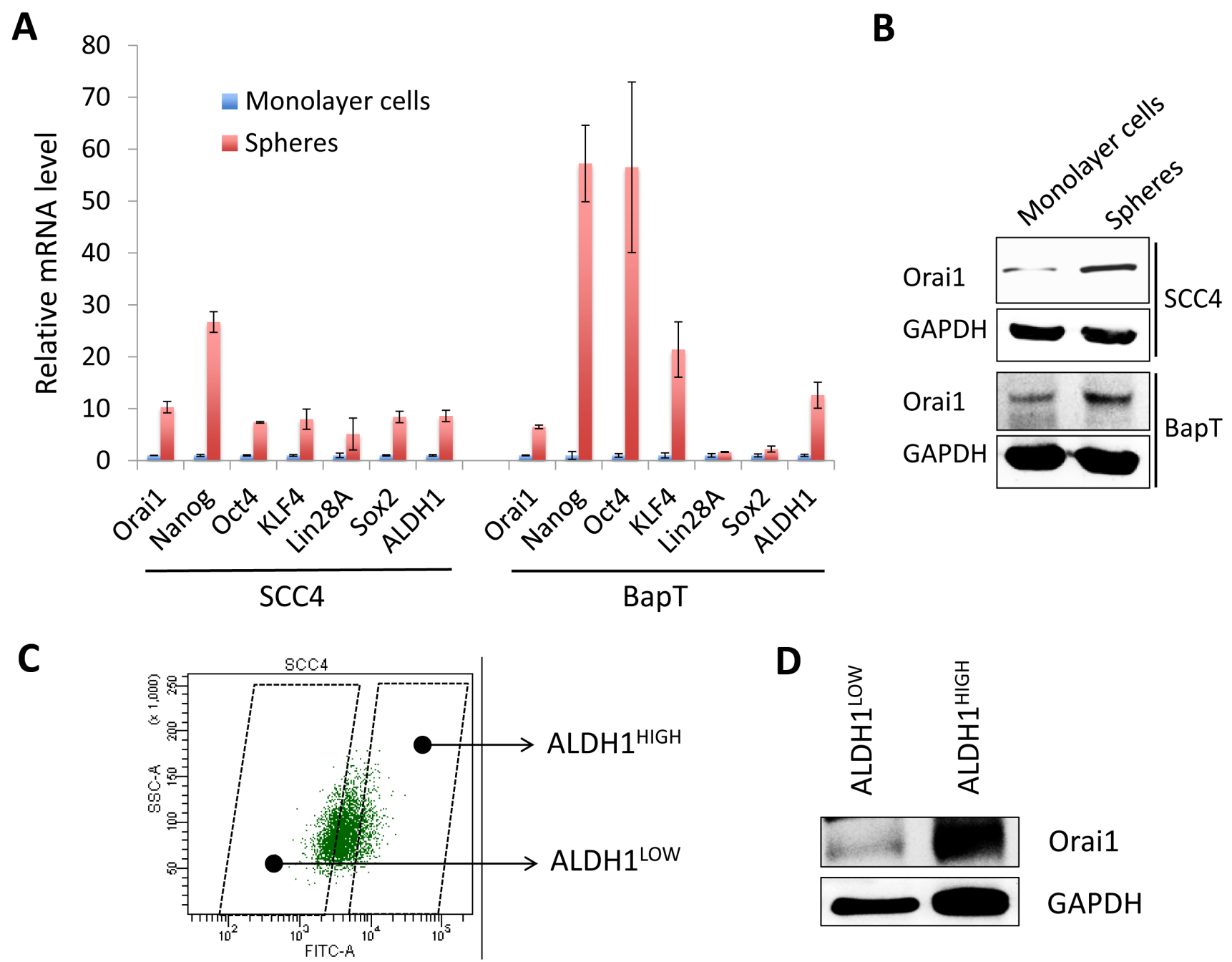

Figure 4: Orai1 expression is enriched in CSC populations of OSCC. A. Expressions of Orai1, stemness transcription factors (Nanog, Oct4, KLF4, Lin28A, and Sox2) and ALDH1were assessed in tumor spheres (CSC-enriched population) and corresponding adherent monolayer cells (non-CSC population) derived from SCC4 and HOK-16B BapT by real-time qPCR. Levels of the genes were normalized with the level of GAPDH. Their levels in tumor spheres were plotted as fold induction against those in their corresponding adherent monolayer cells. B. Level of Orail protein was assessed in tumor spheres and corresponding adherent monolayer cells by Western blot analysis. C. Demonstration of the strategy for sorting ALDH1 ${ }^{\mathrm{HIGH}}$ (CSC-enriched population) and ALDH1 ${ }^{\mathrm{LOW}}$ (non-CSC population) cell population. $\mathrm{ALDH} 1^{\mathrm{HIGH}}$ and $\mathrm{ALDH} 1^{\mathrm{LOW}}$ cell populations were sorted from SCC4 cells by flow cytometry. D. Level of Orail protein was determined in ALDH1 $1^{\mathrm{HIGH}}$ and ALDH $1^{\mathrm{LOW}}$ cell population by Western blot analysis. 
HOK-16B/Orai1. The NFAT inhibitor also suppressed self-renewal and migration in OSCC cells (Supplementary Figure 3). Our data indicate that NFAT signaling is required for Orail-induced CSC phenotype.

Four isoforms of NFAT, NFATc1, NFATc2, NFATc3, and NFATc4, were identified [49]. To determine which of the NFAT isoforms are involved in Orail-induced CSC phenotype, we first examined the expressions of the isoforms in HOK-16B/EV and HOK-16B/Orai1. Among these four members, we found that NFATc3 was the dominant isoform and increased by Orail in HOK-16B (Figure 7C). Moreover, knockdown of Orail reduced the expression of NFATc3 (Supplementary Figure 2A). We also found that NFATc 3 is the dominant isoform in various OSCC cell lines (data not shown). Notably, NFATc3 was primary found in the cytoplasm of $\mathrm{HOK}-16 \mathrm{~B} / \mathrm{EV}$ but accumulated in the nucleus of HOK-16B/Orail (Figure 7D and 7E), indicative of NFATc3 activation by Orai1 [47].

To further assess the functional role of NFATc3 in Orail-induced CSC phenotype, we knocked down NFATc3 using siRNA in HOK-16B/Orail (Figure 7F). Knockdown of NFATc3 showed significant suppressive effect on tumor sphere formation (Figure $7 \mathrm{G}$ ) and migration (Figure $7 \mathrm{H})$ in $\mathrm{HOK}-16 \mathrm{~B} /$ Orail cells. Consistent with this, we also demonstrated that silencing of NFATc3 resulted in significant suppression of tumor sphere formation and migration ability in OSCC cells (Supplementary Figure 4). Our findings indicate that Orail promotes CSC phenotype through NFATc3, suggesting the role of Orai1/NFAT axis in CSC regulation.
A

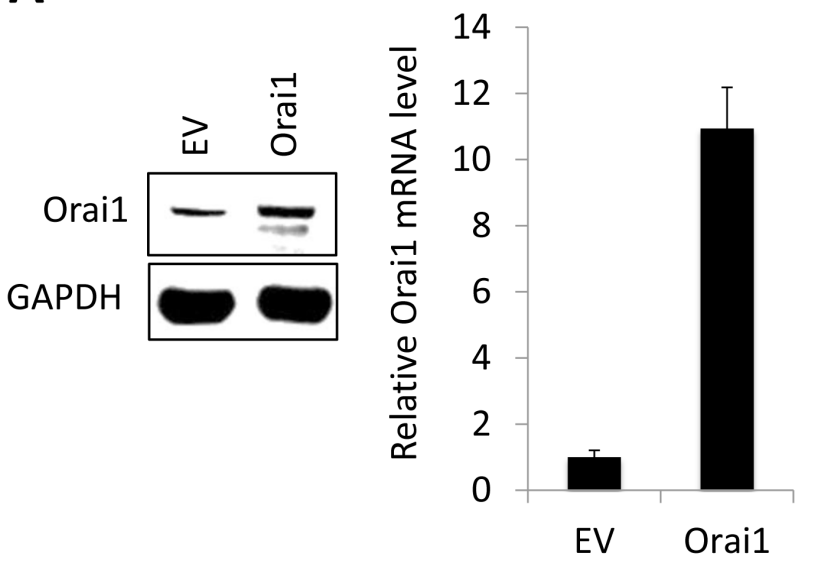

C

\begin{tabular}{|l|c|}
\hline Group & In vivo tumorigenicity \\
\hline HOK-16B/EV & $0 / 5$ \\
\hline HOK-16B/Orai1 & $3 / 5$ \\
\hline
\end{tabular}

HOK-16B/EV

HOK-16B/Orai1

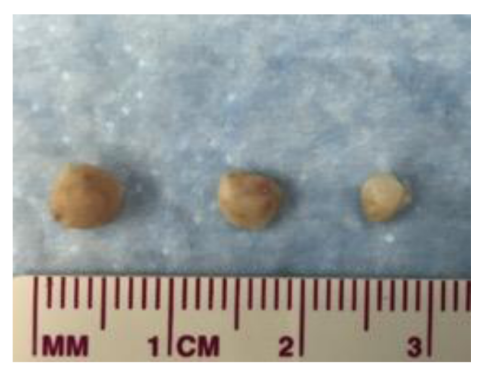

B

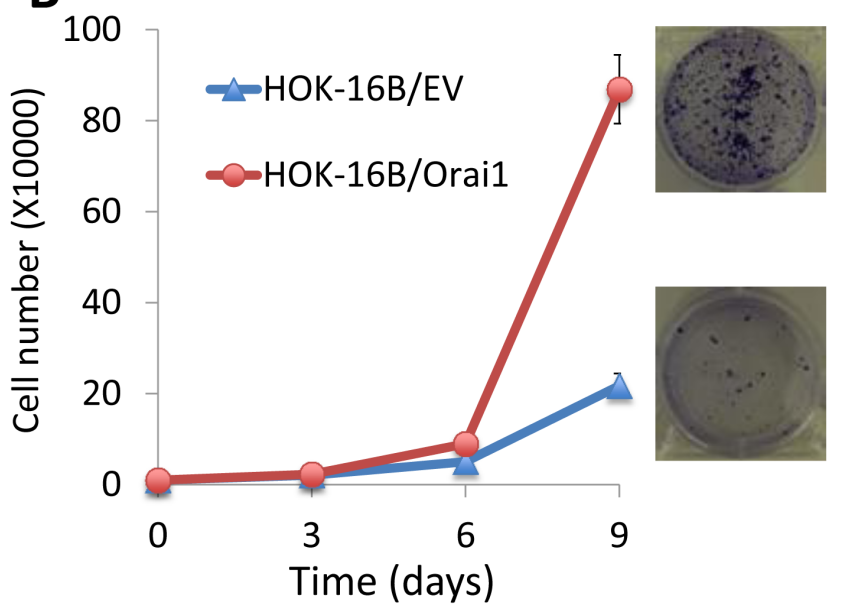

D

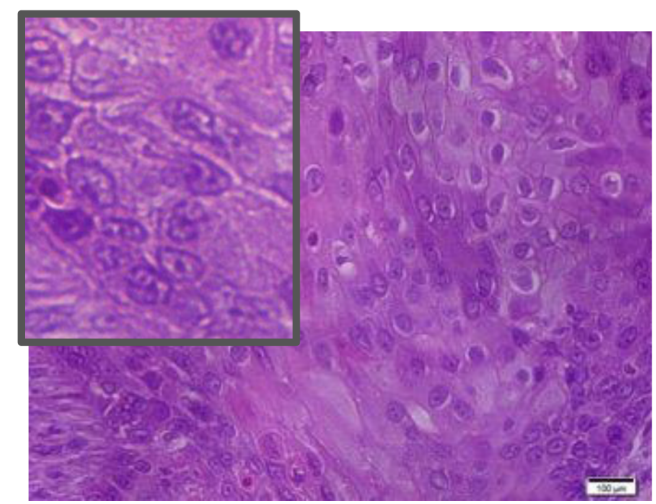

Figure 5: Ectopic Orai1 expression endows non-tumorigenic immortalized oral epithelial cells with tumorigenic potential in vivo. A. Orail expression was forced in non-tumorigenic immortalized oral epithelial cells, HOK-16B, by infecting with retroviral vector expressing Orail, and its ectopic expression was confirmed by Western blot analysis (Left) and real-time qPCR (Right). B. Effect of Orail on cell proliferation of HOK-16B was determined by cell counting. Data are means \pm SD of triplicate experiments. Representative images of clonogenic assay are also shown on the right. C. Effect of Orail on in vivo tumorigenicity of HOK-16B was determined by xenograft tumor assay. HOK-16B/EV and HOK-16B/Orail were injected subcutaneously into five nude mice. Mice were killed at week 6, and tumors were surgically removed from all animals and photographed. D. Morphology characteristics of xenografts formed by HOK-16B/Orail were observed via hematoxylin and eosin (H\&M) staining. Insert showing magnified image. 


\section{DISCUSSION}

In this study, we demonstrate for the first time that Orai1 is a novel molecular regulator of tumorigenicity and stemness of OSCC. Orail expression is elevated in a stepwise manner during oral/oropharyngeal carcinogenesis and enriched in CSC populations. Ectopic Orail expression confers in vivo tumorigenic capacity and CSC phenotype on non-tumorigenic immortalized oral epithelial cells. Moreover, inhibition of Orail suppresses tumorigenicity and CSC phenotype in OSCC. We also provide the evidence that Orail enhances CSC phenotype through NFAT signaling, indicating the importance of Orai1/NFAT axis in oral CSC. Therefore, our study highlights the functional significance of Orail signaling in malignant progression of OSCC by enriching cancer stemness.

Emerging role of Orai1 in human cancer has been reported. Upregulation of Orai1 expression was observed in various human cancers, including esophageal cancer [34]. A high expression of Orail protein is also strongly linked to poor prognosis and aggressive behavior of
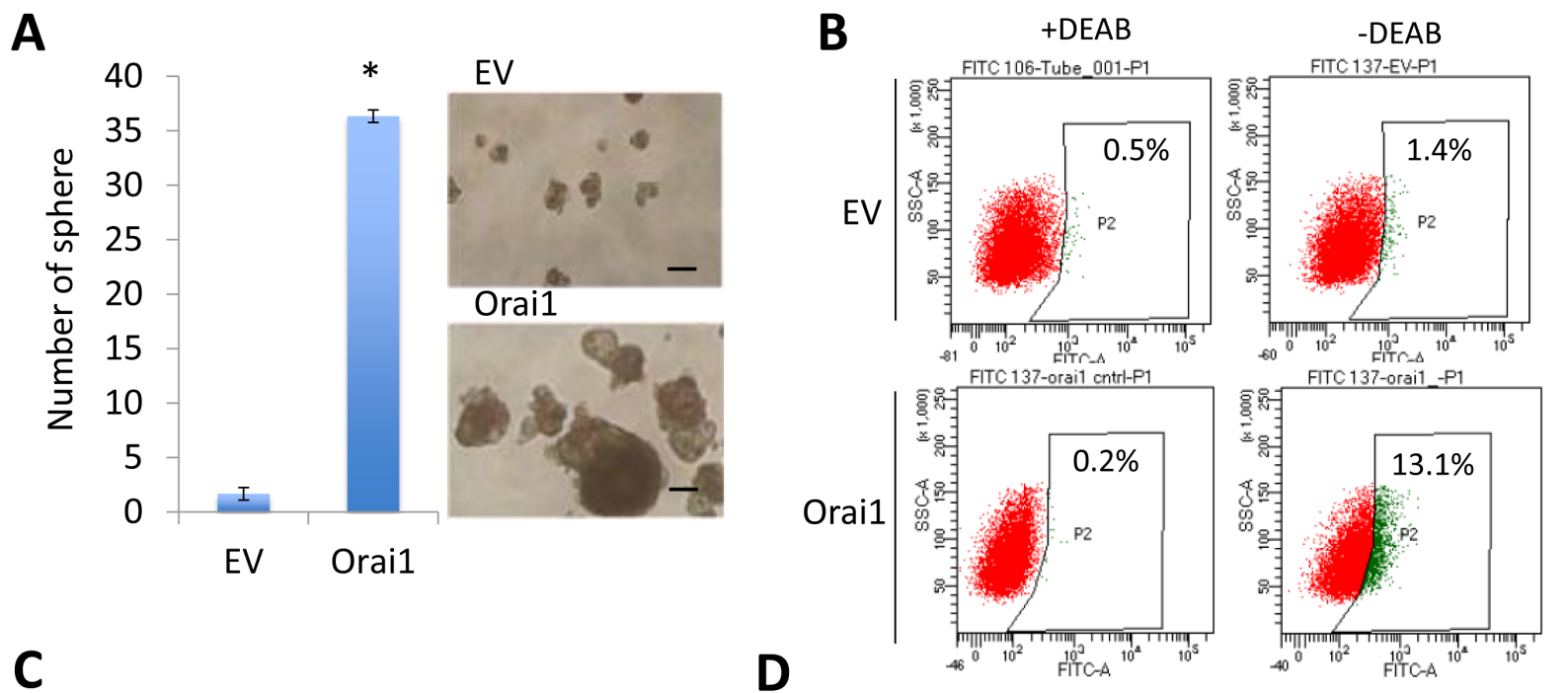

C
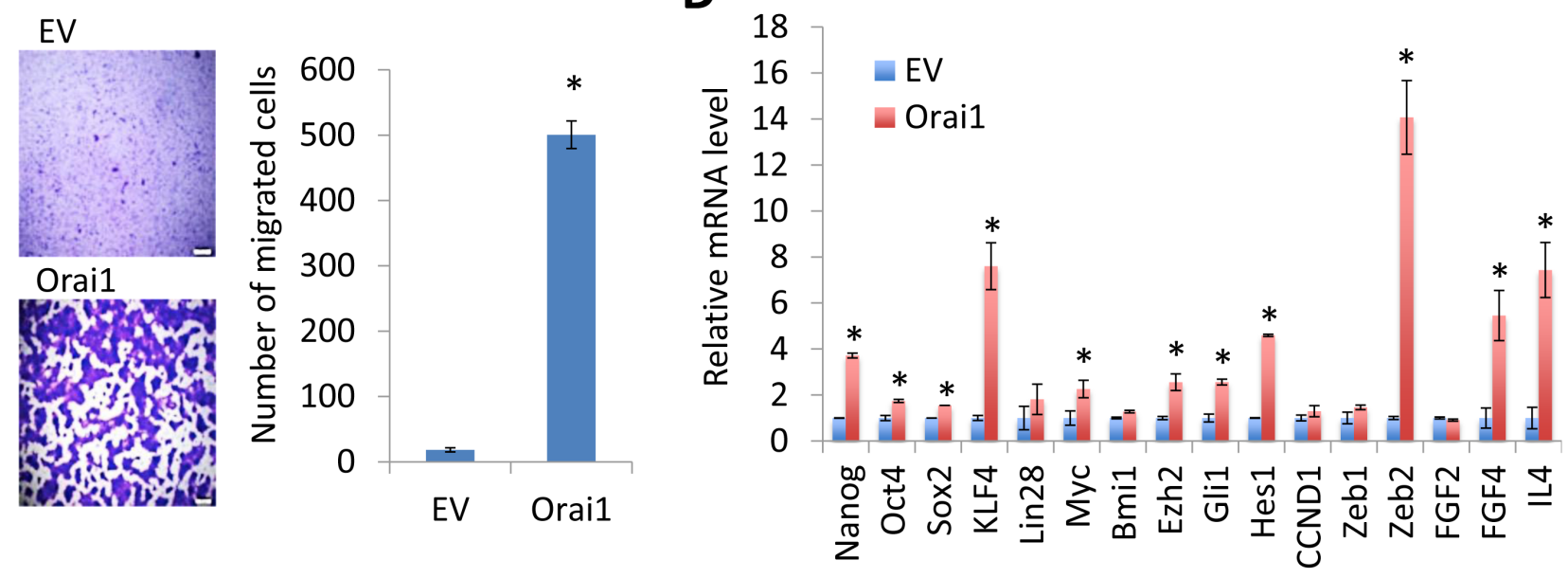

Figure 6: Ectopic Orai1 expression promotes CSC phenotype in non-tumorigenic immortalized oral epithelial cells. A. Effect of Orail on self-renewal capacity of HOK-16B was determined by tumor sphere formation assay. $* P<0.01$ by two-tailed Student's $t$ test. Representative image of tumor spheres formed by HOK-16B/EV and HOK-16B/Orail are shown on the right. Bar indicates $100 \mu \mathrm{m}$. B. Effect of Orail on ALDH1 activity in HOK-16B was determined by Aldefluor assay. Cells were labeled with Aldefluor combined with or without the ALDH1 inhibitor DEAB and analyzed by flow cytometry. The gate for ALDH1 + cells is determined in relation to the DEAB control (+DEAB) and shows the brightly fluorescent ALDH1 population versus the side scatter, a population that is absent/decreased in the presence of DEAB. The number shown in each panel reflects the percentage of ALDH1+ cells in each cell type. C. Effect of Orail on migration ability in HOK-16B was determined by transwell migration assay. ${ }^{*} P<0.001$ by two-tailed Student's $t$ test. Representative images of transwell migration assay are shown on the left. D. Effects of Orail on stemness transcription factors (Nanog, Oct4, Sox2, KLF4, Lin28, Myc, and Bmi1) and CSC-related genes (Ezh2, Gli1, Hes1, CCND1, Zeb1, Zeb2, FDF2, FGF4, and IL4) in HOK-16B were determined by real-time qPCR. Their levels in HOK-16B/Orail were plotted as fold induction against those in $\mathrm{HOK}-16 \mathrm{~B} / \mathrm{EV}$. ${ }^{*} P<0.05$ by two-tailed Student's $t$ test. 
A

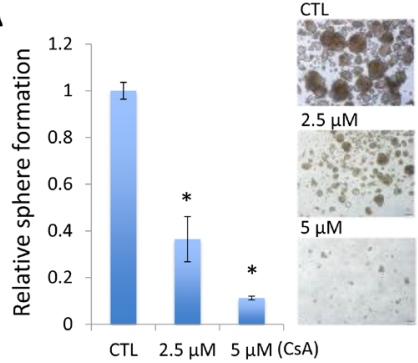

B

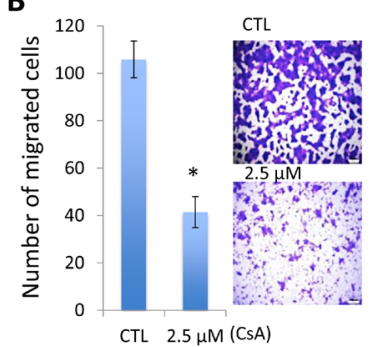

C

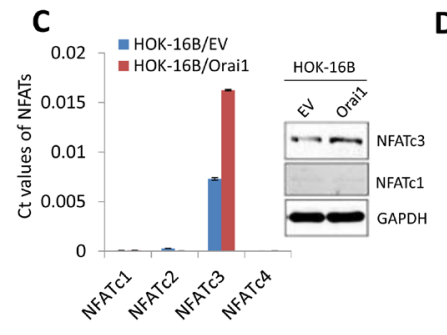

$\mathbf{F}$

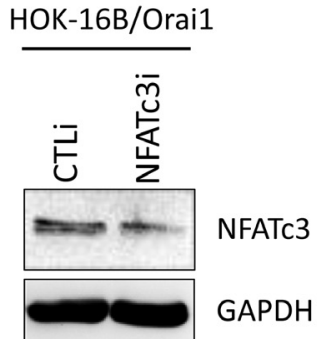

D

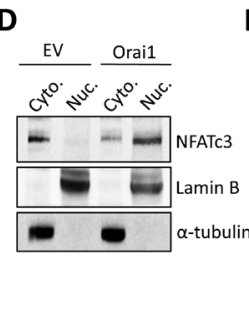

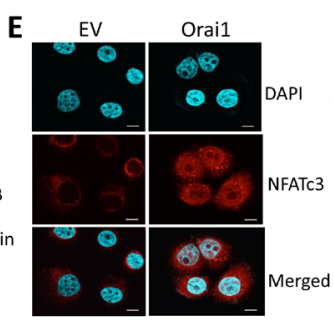

G

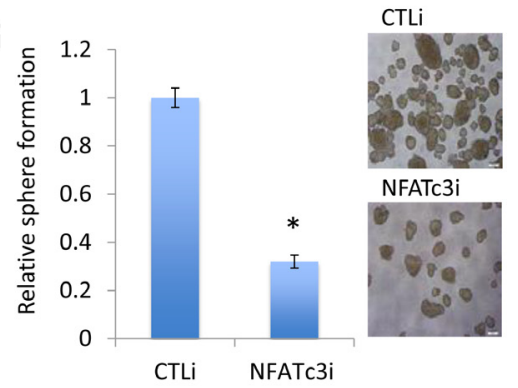

H

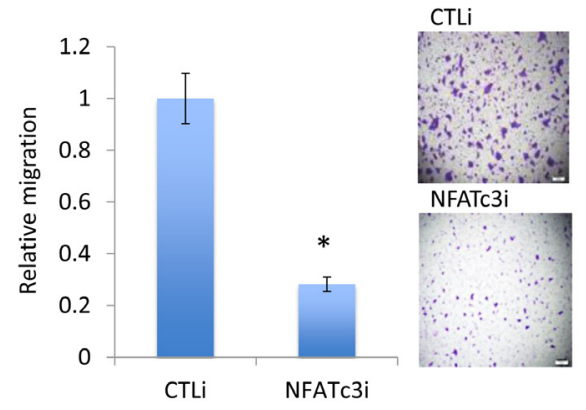

Figure 7: NFAT signaling is required for Orai1-induced CSC phenotype. A. Effect of NFAT antagonist, cyclosporine A (CsA), on self-renewal capacity of HOK-16B/Orail was determined by tumor sphere formation assay. $* P<0.05$ by two-tailed Student's $t$ test. Representative images of tumor spheres formed by HOK-16B/Orail exposed to the NFAT inhibitor are shown on the right. B. Effect of the NFAT inhibitor on migration ability in HOK-16B/Orai1 was determined by transwell migration assay. ${ }^{*} P<0.05$ by two-tailed Student's $t$ test. Representative images of transwell migration assay are shown on the right. C. Effect of Orailon the expression of NFAT isoforms (NFATc1, NFATc2, NFATc3, and NFATc4) in HOK-16B was determined by real-time qPCR (left) and Western blot analysis (right). The Ct values for 4 NFAT isoforms were normalized by the CT value of GAPDH. D. Effect of Orail on the intracellular localization of NFATc3 was determined by Western blot analysis using the cytoplasmic (Cyto.) and nuclear (Nuc.) extracts. Lamin B is a nuclear protein. $\alpha$-tubulin is a cytoplasmic protein. E. Effect of Orail on the intracellular localization of NFATc3 was determined by confocal laser scanning microscopy. After cell permeabilization and blocking, cells were probed with NFATc3 primary antibody overnight, then with Alexa Fluor 594 dyeconjugated secondary antibody and DAPI (blue-green) for confocal laser scanning. HOK-16B/EV has NFATc3 immunofluorescence staining (red) mainly in the cytoplasm while HOK-16B/Orail has stronger staining both in the cytoplasm and the nucleus, which indicates increased NFATc3 expression as well as dominant nuclear translocation. Representative images were taken at 60x. F. Endogenous NFATc3 was knocked down in HOK-16B/Orail using siRNA against NFATc3 (NFATc3i). The cells transfected with control siRNA (CTLi) were included for comparison. Knockdown of NFATc3 was confirmed by Western blot analysis. G. NFATc3 knockdown effect on self-renewal capacity of HOK-16B/Orail was determined by tumor sphere formation assay. Representative images of tumor spheres formed by HOK16B/Orail transfected with control siRNA (HOK-16B/Orai1/CTLi) and NFATc3 siRNA (HOK-16B/Orai1/NFATc3i) are shown on the right. H. NFATc3 knockdown effect on migration ability in HOK-16B/Orail was determined by transwell migration assay. $* P<0.05$ by two-tailed Student's $t$ test. Representative images of transwell migration assay are shown on the right. Bar indicates $100 \mu \mathrm{m}$. 
human cancers. However, no information is available regarding Orail expression during oral/oropharyngeal carcinogenesis. Our results showed that Orail is highly expressed in OSCC compared to precancerous and normal tissues in vivo. Moreover, precancerous oral epithelial cells express higher Orail protein than normal oral epithelial cells, suggesting that Orail plays an important role in cancer progression. To our knowledge, our finding is the first report showing a stepwise elevation of Orail in multistep carcinogenesis in vivo and further oncogenic transformation of immortalized cells by Orail overexpression. Consistent with previous observation [34], our immunohistochemistry study confirmed localization of Orail in the plasma membrane. We also observed diffused staining of Orail in both the cytoplasm and nucleus. Since the tissue sections were obtained from 3 dimensional tissue structures, there could be some overlap with another cell layer positioned in different orientation compared to monolayer-cultured cells. Indeed, we were able to detect predominant Orail staining to the plasma membrane in the monolayer-cultured cells of HOK-16B/ Orail (data not shown). Our study clearly demonstrated that Orail is required for tumorigenicity of OSCC in vivo. Inactivation of Orail by the dominant negative Orai1 mutant not only suppressed SOCE, but also abolished in vivo tumorigenic potential of OSCC. Conversely, ectopic Orai1 expression further transformed non-tumorigenic oral epithelial cells to tumorigenic cells. This finding is consistent with the results of a previous study reporting that Orail inhibition led to significant decreases in cancer growth in vivo and in vitro [32-34]. Our findings support the hypothesis that Orail is a novel molecular determinant of oral/oropharyngeal cancer progression.

Self-renewal is the critical characteristic by which CSCs regenerate themselves, suggesting the driving force of tumorigenesis. CSCs are viewed as the seed of cancer and hence as effective target of anti-cancer therapies. Therefore, findings from our studies are of paramount important for the development of more effective cancer therapies. By phenotypic and functional analysis, we demonstrate that Orail is an important regulator of CSC phenotype in OSCC. Orail is highly expressed in CSCenriched cell populations, such as tumor spheres and ALDH $1^{\mathrm{HIGH}}$ population of OSCC. Furthermore, Orai1 endowed non-tumorigenic immortalized oral epithelial cells with self-renewal and concomitantly increased stemness transcription factors, i.e., Nanog, Oct4, Sox2, KLF4, and Myc. Orail also promoted other CSC properties, ALDH1 activity and migration. Ectopic Orai1 expression markedly increases ALDH1+ cell population in the non-tumorigenic oral epithelial cells. ALDH1 has been found to be a marker for stem cells in different types of cancer, including OSCC $[50,51]$. ALDH1+ cancer cells displayed higher self-renewal, migration, and tumorigenic potential than ALDH1- cells [50, 52, 53]. Orai1 also markedly increases motility of the non-tumorigenic cells.
Our finding is consistent with previous reports showing the importance of Orail in cell migration. Knockdown of Orail in invasive breast cancer cell lines decreased cell migration, whereas its overexpression promoted cellular motility [36]. However, underlying mechanism by which Orail enhances oral epithelial cell migration has not been understood. Therefore, effects of Orail on epithelial-tomesenchymal transition (EMT) and metastasis-related gene expression should be warranted to investigate [54]. In multiple OSCC cell lines, inhibition of Orail led to suppression of such CSC phenotype. We conclude that Orail increases not only the number of CSCs, but also CSC properties. Thus, we hypothesize that Orai1 promotes malignant progression of OSCC by enriching CSC phenotype. Therefore, Orail could be an effective therapeutic target for OSCC.

We also found that Orail regulates the expression of several important CSC-related genes, i.e., Ezh2, Gli1, Hes1, Zeb2, FGF4, and IL4. Studies have shown the important role of these genes in acquisition and maintenance of CSC phenotype. For instance, our previous study demonstrated that Hes1 is upregulated in OSCC, and the suppression of Hes 1 in oral cancer cells inhibits self-renewal capacity of OSCC, suggesting the important role of Hes 1 in OSCC CSC [55]. In addition, other reports also revealed the crucial roles of Hes 1 in the maintenance of CSC properties, such as metastasis, chemotherapy resistance, and EMT [56]. Zeb1 and Zeb2 are significantly increased in head and neck CSCs compared to non-CSCs [57]. Knockdown of Zeb1 and Zeb2 in head and neck cancer cells decreased their CSC properties such as selfrenewal capacity, the expression of stemness markers, and drug resistance. Moreover, their suppression inhibited in vivo tumor growth and the rate of metastasis to distant site [57]. Conversely, co-overexpression of Zeb1 and Zeb2 enhanced sphere-forming ability of head and neck cancer cells [57]. FGF4 is shown to play a key role in maintaining self-renewal capacity of normal and cancer stem cells $[58,59]$. FGF4 promoted self-renewal of CSC-enriched population [59].

Many studies demonstrated that cytokines increased CSC population and phenotype [55, 60-63]. We also reported that inflammatory cytokine enhanced CSC phenotype of OSCC [55]. Recently, to investigate the roles of cytokines in CSCs of OSCC, we profiled expression of 25 cytokines and found that IL4 was highly increased in tumor spheres compared to corresponding adherent monolayer cells (manuscript in preparation). IL4 is overexpressed in different types of cancer including breast, ovarian, colon, lung, and thyroid [64]. Moreover, recent studies revealed crucial role of IL4 in the maintenance of CSC $[61,65,66]$. We found that IL4 expression is upregulated by Orai1 and downregulated by inhibition of Orail. Since IL4 is a well-known target of NFAT, the major downstream effector molecule of Orai1 [67, 68], we speculate a possible role of Orail-NFAT-cytokine(s) 
axis in CSC regulation; however, further investigation will be necessary to examine the functional roles of cytokines, e.g., IL4, in CSC regulation by Orai1/NFAT axis.

Orail-mediated SOCE activates NFAT, a family of transcription factors composed of four members, NFATc1, NFATc2, NFATc3, and NFATc4 [27, 28, 49]. Emerging evidence has suggested that NFAT signaling plays an important role in tumorigenesis by regulating various target genes involved in cancer development [47]. For instance, NFATc1 induced malignant cell growth phenotype in pancreatic cancer cells by upregulating Myc [69] and promoted metastasis of mammalian cancer cells via MMP-2 upregulation [70-72]. NFATc2 was overexpressed in multiple cancer types $[71,72]$, and its depletion suppressed migration/invasion of cancer cells [71]. However, the role of NFAT proteins in OSCC has not been documented. Treatment of OSCC cells with NFAT inhibitor suppressed self-renewal and migration. Similar effect of the NFAT inhibitor was also observed in HOK-16B/Orai1, suggesting that NFAT is required for Orail-induced CSC phenotype. Furthermore, our studies revealed that NFATc3 is dominant isoform in oral epithelial cells and activated by Orail overexpression. Silencing NFATc3 in HOK-16B/Orail led to suppression of CSC phenotype, suggesting the funtional role of Orail/ NFAT axis in the regualtion of CSC.

There is emerging evidence suggesting that spatio-temporal regulation calcium signaling (calcium oscillation) is more important than global changes in cytosolic calcium concentration in the context of tumor invasion, growth and cancer cell stemness [34, 73, 74]. Calcium oscillation is the result of SOCE. Orail is the dominant isoform in OSCC and enriched in OSCC CSCs. Although our work has not demonstrated the calcium oscillation change in Orail-overexpressing cells, we have shown that inhibiting Orail channel function resulted in complete shutdown of the calcium oscillation.

In conclusion, Orai1 is a novel molecular regulator of tumorigenicity and stemness of OSCC. Orail enhances CSC phenotype through NFAT signaling. Thus, the Orail/ NFAT axis could be an important therapeutic target in OSCC. Since Orail is readily inhibited by small molecular inhibitor [46], targeting Orail signaling may be a plausible therapeutic modality against cancer.

\section{MATERIALS AND METHODS}

\section{Cell culture and reagents}

Primary normal human oral keratinocytes (NHOK) were prepared from oral mucosa and cultured in Keratinocyte Growth Medium (KGM, Lonza) as described previously [75]. Three non-tumorigenic immortalized oral epithelial cell lines, NOK-SI [76], OKF6/tert [77], and $\mathrm{HOK}-16 \mathrm{~B}$ [75], were also cultured in KGM. Ten human OSCC cell lines, HOK-16B BapT, SCC4 [78], SCC15, SCC1, SNU1041, SNU1076, SCC9/TNF [55], YD9 [79], YD15M, and UM17b [80], were cultured in DMEM/Ham's F12 (Invitrogen) supplemented with 10\% FBS (Gemini Bioproducts) and $0.4 \mu \mathrm{g} / \mathrm{ml}$ hydrocortisone (Sigma-Aldrich). Orail chemical blocker, Compound 5D [46], was obtained from Dr. Yousang Gwack (UCLA David Geffen School of Medicine). Antagonist of NFAT signaling, cyclosporine A (CsA), was purchased from Sigma-Aldrich.

\section{Western blotting}

Western blotting was performed as described previously [55]. We used the following primary antibodies for our study: Orai1 (AB9868; EMD Millipore), NFATc3 (sc-8405; Santa Cruz Biotech), NFATc1 (8032S; Cell Signaling Tech), Lamin B1 (sc-20682; Santa Cruz Biotech), $\alpha$-tubulin (T9026; Sigma) and GAPDH (FL335; Santa Cruz Biotech). Cytoplasmic and nuclear proteins were isolated using the NE-PER ${ }^{\circledR}$ Nuclear and Cytoplasmic Extraction Reagents kit (Pierce, Rockford) following the manufacturer's instructions.

\section{Immunohistochemistry}

Tissue specimens that were previously collected for diagnostic purposes were obtained from the Oral Pathology Diagnostic Laboratory at the UCLA School of Dentistry. All tissue specimens were collected and processed according to the guidelines of the University of California at Los Angeles Institutional Review Board. Immunohistochemical staining was performed as described previously [81]. The optimal concentration (1:100) of Orail antibody (AB9868; EMD Millipore) was first established using serially diluted primary antibody along with IgG as a negative control. Two independent examiners scored the immunohistochemical expression of Orail protein. The level of Orail staining pattern was scored into four subgroups: (1) weak; (2) moderate; and (3) strong $(+++)$; (4) very strong.

\section{Confocal laser scanning microscopy}

Five thousand cells were seeded on the 4 chamber slides (Thermo Fisher Scientific) one day prior to the immunofluorescence staining. After cell permeabilization and blocking, cells were probed with NFATc3 primary antibody overnight, then with Alexa Fluor 594 dyeconjugated secondary antibody and DAPI (blue-green) for confocal laser scanning. Confocal laser scanning microscopy was performed using Fluoview FV10i Confocal Microscope (Olympus), and images were 
captured with $60 \mathrm{x}$ oil objective under different gain settings. The laser diode $559 \mathrm{~nm}$ was used to capture NFATc3 staining, and the diode $405 \mathrm{~nm}$ laser was used to capture DAPI nuclear stain. Image acquisition and further adjustment of brightness was performed using Olympus Fluoview Ver. 4.2a. Fluorescent images of cells were taken as single channel images then converted to overlay images and all images were saved in TIFF format.

\section{Ectopic expression of dominant negative Orai1 E106Q mutant and wild-type Orai1}

The retroviral pMSCV-CITE-eGFP-Puro vectors encoding ORAI1 ${ }^{\text {WT }}$ and ORAI1 ${ }^{\text {E106Q }}$ [26] were used to prepare viruses as described previously [82]. These vectors were transfected into GP2-293 universal packaging cells (Clonetech, Mountain View, CA, USA) along with pVSV-G envelope plasmid using lipofectamine 2000 (Life Technologies). Detailed methods of retrovirus production and infection can be found in our previous publications [83]. Infected cells were selected with $0.5 \mu \mathrm{g} /$ $\mathrm{ml}$ puromycin for two weeks and used for experiments.

\section{SOCE assay (Single-cell $\mathrm{Ca}^{2+}$ imaging)}

Cells were plated on UV-sterilized coverslips one day prior to imaging. Next day, cells were loaded with 1 $\mathrm{mM}$ Fura $2-\mathrm{AM}$ for $45 \mathrm{~min}$ at $25^{\circ} \mathrm{C}$. Intracellular $\left[\mathrm{Ca}^{2+}\right]_{\mathrm{i}}$ measurements were performed using essentially the same methods as previously described [84].

\section{Anchorage-independent growth}

To determine colony-forming efficiency in semisolid medium, $1 \times 10^{4}$ cells were plated in culture medium containing $0.3 \%$ agarose over a base layer of serumfree medium containing $0.5 \%$ agarose. The assay was performed as described previously [55].

\section{In vivo xenograft tumor assay}

Five-ten million cells were subcutaneously injected into the flank of immunocompromised mice (strain $n u$ / $n u$, Charles River Laboratories). The animal study was performed according to the protocol approved by UCLA Animal Research Committee. The kinetics of tumor growth was determined by measuring the volume in three perpendicular axes of the nodules using micro-scaled calipers.

\section{Tumor sphere formation assay}

Three thousand cells were grown in $3 \mathrm{ml}$ of serumfree DMEM/F12 media supplemented with 1:50 B27 (Invitrogen), $20 \mathrm{ng} / \mathrm{mL}$ EGF, $20 \mathrm{ng} / \mathrm{mL}, 10 \mu \mathrm{g} / \mathrm{mL}$ insulin, penicillin, streptomycin, and amphotericin B in Ultra-Low Attachment 6-well Plates (Corning) for 6-10 days [55].

\section{Quantitative real-time PCR (qPCR)}

cDNA was synthesized from $5 \mu \mathrm{g}$ of total RNA using SuperScript first-strand synthesis system (Invitrogen). We used $1 \mu \mathrm{l}$ cDNA for qPCR amplification using SYBR Green I Master mix (Roche) and LightCycler 480 II (Roche). The primer sequences were obtained from the Universal Probe Library (Roche), and the sequences can be available upon request. Second derivative $\mathrm{Cq}$ value determination method was used to compare folddifferences according to the manufacturer's instructions.

\section{ALDH1 assay}

Using Aldehyde Dehydrogenase-Based Cell Detction Kit (STEMCELL), ALDH enzymatic activity was determined. Total of $1 \times 10^{6}$ cells were re-suspended in the ALDEFLUOR Assay Buffer in the volume of $1 \mathrm{ml}$. Fluorescent nontoxic ALDEFLUOR Reagent BODIPY ${ }^{\mathrm{TM}}$ $(1.25 \mu \mathrm{l})$ was added as a substrate to measure ALDH enzymatic activity in intact cells. Immediately after adding the substrate reagent, $0.5 \mathrm{ml}$ of the cell suspension was transferred into the control tube which contains specific inhibitor for ALDH, diethylaminobenzaldehyde (DEAB) for calculating background fluorescence. Then, cells were incubated at $35^{\circ} \mathrm{C}$ for 30 minutes and fluorescence data acquisition was made by using a BD FACScan flow cytometer (BD Biosciences).

\section{Migration and invasion assays}

Cell migration was measured using transwell chambers with polycarbonate membranes (Corning) as described in our previous publication [55]. Cell invasion was measured using Matrigel Basement Membrane Matrix (BD Biosciences), according to the method as described in manufacture protocol.

\section{Knockdown of NFATc3}

NFATc3 was knocked down by duplex siRNA targeting NFATc 3 or the control, scrambled siRNA (Santa Cruz Biotech), which was introduced using Lipofectamine RNAiMAX (Invitrogen). Cells (2 x 10 $)$ were plated in $60-\mathrm{mm}$ dishes and transfected with $15 \mu \mathrm{g}$ siRNA. The 
cultures were harvested after two days post-transfection for expression and functional analyses.

\section{Abbreviations}

OSCC, Oral/oropharyngeal squamous cell carcinomas; CSCs, Cancer stem cells; SOCE, storeoperated $\mathrm{Ca} 2+$ entry; NHOE, Normal human oral epithelia; ALDH1, Aldehyde dehydrogenase 1; NFAT, nuclear factor of activated T cells; IL4, Interleukin 4; siRNA, small interfering RNA; IHC, immunohistochemistry

\section{ACKNOWLEDGMENTS}

This work was supported in part by the grant UCLA School of Dentistry faculty seed grant (to K.H.S.), the grant (R01DE18295 to M.K.K.), the grant (R01DE023348 to R.H.K.) from NIDCR/NIH, the grant (R01AI083432 to Y.G) from NIAID/NIH, and the grant from UCLA Chancellor's Office (to N.H.P.).

\section{CONFLICTS OF INTEREST}

The authors declare no potential conflicts of interest.

\section{Editorial note}

This paper has been accepted based in part on peerreview conducted by another journal and the authors' response and revisions as well as expedited peer-review in Oncotarget.

\section{REFERENCES}

1. Al-Swiahb JN, Chen CH, Chuang HC, Fang FM, Tasi HT and Chien CY. Clinical, pathological and molecular determinants in squamous cell carcinoma of the oral cavity. Future Oncol. 2010; 6:837-850.

2. Lee CH, Lee JM, Wu DC, Hsu HK, Kao EL, Huang HL, Wang TN, Huang MC and Wu MT. Independent and combined effects of alcohol intake, tobacco smoking and betel quid chewing on the risk of esophageal cancer in Taiwan. Int J Cancer. 2005; 113:475-482.

3. Perez-Sayans M, Somoza-Martin JM, Barros-Angueira F, Reboiras-Lopez MD, Gandara Rey JM and Garcia-Garcia A. Genetic and molecular alterations associated with oral squamous cell cancer (Review). Oncology reports. 2009; 22:1277-1282.

4. Warnakulasuriya S, Reibel J, Bouquot J and Dabelsteen E. Oral epithelial dysplasia classification systems: predictive value, utility, weaknesses and scope for improvement. J Oral Pathol Med. 2008; 37:127-133.

5. Brennan M, Migliorati CA, Lockhart PB, Wray D, Al-
Hashimi I, Axell T, Bruce AJ, Carpenter W, Eisenberg E, Epstein JB, Holmstrup P, Jontell M, Nair R, Sasser H, Schifter M, Silverman B, et al. Management of oral epithelial dysplasia: a review. Oral Surg Oral Med Oral Pathol Oral Radiol Endod. 2007; 103 Suppl:S19 e11-12.

6. Marcial VA, Pajak TF, Mohiuddin M, Cooper JS, al Sarraf M, Mowry PA, Curran W, Crissman J, Rodriguez M and Velez-Garcia E. Concomitant cisplatin chemotherapy and radiotherapy in advanced mucosal squamous cell carcinoma of the head and neck. Long-term results of the Radiation Therapy Oncology Group study 81-17. Cancer. 1990; 66:1861-1868.

7. Beck B and Blanpain C. Unravelling cancer stem cell potential. Nat Rev Cancer. 2013; 13:727-738.

8. Chiou SH, Yu CC, Huang CY, Lin SC, Liu CJ, Tsai TH, Chou SH, Chien CS, Ku HH and Lo JF. Positive correlations of Oct- 4 and Nanog in oral cancer stem-like cells and high-grade oral squamous cell carcinoma. Clin Cancer Res. 2008; 14:4085-4095.

9. Ginestier C, Hur MH, Charafe-Jauffret E, Monville F, Dutcher J, Brown M, Jacquemier J, Viens P, Kleer CG, Liu SL, Schott A, Hayes D, Birnbaum D, Wicha MS and Dontu G. ALDH1 is a marker of normal and malignant human mammary stem cells and a predictor of poor clinical outcome. Cell Stem Cell. 2007; 1:555-567.

10. Liu SL, Dontu G, Mantle ID, Patel S, Ahn NS, Jackson $\mathrm{KW}$, Suri $\mathrm{P}$ and Wicha MS. Hedgehog signaling and Bmi1 regulate self-renewal of normal and malignant human mammary stem cells. Cancer Res. 2006; 66:6063-6071.

11. Giles RH, van Es JH and Clevers H. Caught up in a Wnt storm: Wnt signaling in cancer. Bba-Rev Cancer. 2003; 1653:1-24.

12. Evangelista M, Tian H and de Sauvage FJ. The hedgehog signaling pathway in cancer. Clin Cancer Res. 2006; 12:5924-5928

13. Leong KG and Karsan A. Recent insights into the role of Notch signaling in tumorigenesis. Blood. 2006; 107:22232233.

14. Liu C, Kelnar K, Liu BG, Chen X, Calhoun-Davis T, Li HW, Patrawala L, Yan H, Jeter C, Honorio S, Wiggins JF, Bader AG, Fagin R, Brown D and Tang DAG. The microRNA miR-34a inhibits prostate cancer stem cells and metastasis by directly repressing CD44. Nat Med. 2011; 17:211-U105.

15. Song SJ, Poliseno L, Song MS, Ala U, Webster K, Ng C, Beringer G, Brikbak NJ, Yuan X, Cantley LC, Richardson $\mathrm{AL}$ and Pandolfi PP. MicroRNA-Antagonism Regulates Breast Cancer Stemness and Metastasis via TET-FamilyDependent Chromatin Remodeling. Cell. 2013; 154:311324.

16. Tonelli FM, Santos AK, Gomes DA, da Silva SL, Gomes KN, Ladeira LO and Resende RR. Stem cells and calcium signaling. Advances in experimental medicine and biology. 2012; 740:891-916. 
17. Kawano S, Shoji S, Ichinose S, Yamagata K, Tagami M and Hiraoka M. Characterization of $\mathrm{Ca}(2+)$ signaling pathways in human mesenchymal stem cells. Cell Calcium. 2002; 32:165-174.

18. Apati A, Paszty K, Erdei Z, Szebenyi K, Homolya L and Sarkadi B. Calcium signaling in pluripotent stem cells. Molecular and cellular endocrinology. 2012; 353:57-67.

19. Berridge MJ, Bootman MD and Roderick HL. Calcium signalling: dynamics, homeostasis and remodelling. Nat Rev Mol Cell Biol. 2003; 4:517-529.

20. Monteith GR, McAndrew D, Faddy HM and RobertsThomson SJ. Calcium and cancer: targeting Ca2+ transport. Nat Rev Cancer. 2007; 7:519-530.

21. Roderick HL and Cook SJ. Ca2+ signalling checkpoints in cancer: remodelling $\mathrm{Ca} 2+$ for cancer cell proliferation and survival. Nat Rev Cancer. 2008; 8:361-375.

22. Prevarskaya N, Skryma R and Shuba Y. Calcium in tumour metastasis: new roles for known actors. Nat Rev Cancer. 2011; 11:609-618.

23. Srikanth S and Gwack Y. (2013). Chapter Eight - Molecular Regulation of the Pore Component of CRAC Channels, Orai1. In: Murali P, ed. Current Topics in Membranes: Academic Press), pp. 181-207.

24. Feske S, Gwack Y, Prakriya M, Srikanth S, Puppel SH, Tanasa B, Hogan PG, Lewis RS, Daly M and Rao A. A mutation in Orail causes immune deficiency by abrogating CRAC channel function. Nature. 2006; 441:179-185.

25. Prakriya M, Feske S, Gwack Y, Srikanth S, Rao A and Hogan PG. Orail is an essential pore subunit of the CRAC channel. Nature. 2006; 443:230-233.

26. Gwack Y, Srikanth S, Feske S, Cruz-Guilloty F, Oh-hora M, Neems DS, Hogan PG and Rao A. Biochemical and functional characterization of Orai proteins. J Biol Chem. 2007; 282:16232-16243.

27. Parekh AB. Functional consequences of activating storeoperated CRAC channels. Cell calcium. 2007; 42:111-121.

28. Parekh AB and Putney JW, Jr. Store-operated calcium channels. Physiological reviews. 2005; 85:757-810.

29. Srikanth S and Gwack Y. Orail-NFAT signalling pathway triggered by $\mathrm{T}$ cell receptor stimulation. Molecules and cells. 2013; 35:182-194.

30. Yang S, Zhang JJ and Huang XY. Orail and STIM1 are critical for breast tumor cell migration and metastasis. Cancer Cell. 2009; 15:124-134.

31. Flourakis M, Lehen'kyi V, Beck B, Raphael M, Vandenberghe M, Abeele FV, Roudbaraki M, Lepage G, Mauroy B, Romanin C, Shuba Y, Skryma R and Prevarskaya N. Orail contributes to the establishment of an apoptosis-resistant phenotype in prostate cancer cells. Cell Death Dis. 2010; 1:e75.

32. Liu H, Hughes JD, Rollins S, Chen B and Perkins E. Calcium entry via ORAI1 regulates glioblastoma cell proliferation and apoptosis. Exp Mol Pathol. 2011; 91:753760.
33. Kim JH, Lkhagvadorj S, Lee MR, Hwang KH, Chung HC, Jung JH, Cha SK and Eom M. Orail and STIM1 are critical for cell migration and proliferation of clear cell renal cell carcinoma. Biochem Biophys Res Commun. 2014; 448:7682.

34. Zhu H, Zhang H, Jin F, Fang M, Huang M, Yang CS, Chen T, Fu L and Pan Z. (2014). Elevated Orail expression mediates tumor-promoting intracellular $\mathrm{Ca} 2+$ oscillations in human esophageal squamous cell carcinoma.

35. Zhan ZY, Zhong LX, Feng M, Wang JF, Liu DB and Xiong JP. Over-expression of Orail mediates cell proliferation and associates with poor prognosis in human non-small cell lung carcinoma. Int J Clin Exp Pathol. 2015; 8:5080-5088.

36. Lee YF, Miller LD, Chan XB, Black MA, Pang B, Ong CW, Salto-Tellez M, Liu ET and Desai KV. JMJD6 is a driver of cellular proliferation and motility and a marker of poor prognosis in breast cancer. Breast Cancer Res. 2012; 14.

37. Zhang J, Ni SS, Zhao WL, Dong XC and Wang JL. High expression of JMJD6 predicts unfavorable survival in lung adenocarcinoma. Tumour biology. 2013; 34:2397-2401.

38. Schmidt S, Liu G, Liu G, Yang W, Honisch S, Pantelakos S, Stournaras C, Hönig A and Lang F. (2014). Enhanced Orai1 and STIM1 expression as well as store operated Ca 2+ entry in therapy resistant ovary carcinoma cells.

39. Lodola F, Laforenza U, Bonetti E, Lim D, Dragoni S, Bottino C, Ong HL, Guerra G, Ganini C, Massa M, Manzoni M, Ambudkar IS, Genazzani AA, Rosti V, Pedrazzoli P, Tanzi F, et al. Store-Operated $\mathrm{Ca}<\sup >2+</$ sup $>$ Entry Is Remodelled and Controls $<$ italic $>$ In Vitro $<$ /italic $>$ Angiogenesis in Endothelial Progenitor Cells Isolated from Tumoral Patients. PLoS ONE. 2012; 7:e42541.

40. Li J, Cubbon RM, Wilson LA, Amer MS, McKeown L, Hou B, Majeed Y, Tumova S, Seymour VAL, Taylor H, Stacey M, O'Regan D, Foster R, Porter KE, Kearney MT and Beech DJ. Orail and CRAC Channel Dependence of VEGF-Activated Ca2+ Entry and Endothelial Tube Formation. Circulation Research. 2011; 108:1190-1198.

41. Beck B and Blanpain C. Unravelling cancer stem cell potential. Nat Rev Cancer. 2013; 13:727-738.

42. Ribatti D. Cancer stem cells and tumor angiogenesis. Cancer Letters. 2012; 321:13-17.

43. Wang Y, Yu Y, Tsuyada A, Ren X, Wu X, Stubblefield K, Rankin-Gee EK and Wang SE. Transforming growth factorbeta regulates the sphere-initiating stem cell-like feature in breast cancer through miRNA-181 and ATM. Oncogene. 2011; 30:1470-1480.

44. Monroe MM, Anderson EC, Clayburgh DR and Wong MH. Cancer stem cells in head and neck squamous cell carcinoma. Journal of oncology. 2011; 2011:762780.

45. Yang N, Tang Y, Wang F, Zhang H, Xu D, Shen Y, Sun $\mathrm{S}$ and Yang G. Blockade of store-operated $\mathrm{Ca}(2+)$ entry inhibits hepatocarcinoma cell migration and invasion by regulating focal adhesion turnover. Cancer Lett. 2013; 
330:163-169.

46. Kim KD, Srikanth S, Tan YV, Yee MK, Jew M, Damoiseaux R, Jung ME, Shimizu S, An DS, Ribalet B, Waschek JA and Gwack Y. Calcium signaling via Orai1 is essential for induction of the nuclear orphan receptor pathway to drive Th17 differentiation. J Immunol. 2014; 192:110-122.

47. Mancini M and Toker A. NFAT proteins: emerging roles in cancer progression. Nat Rev Cancer. 2009; 9:810-820.

48. Martinez-Martinez S and Redondo JM. Inhibitors of the calcineurin/NFAT pathway. Curr Med Chem. 2004; 11:9971007.

49. Daniel C, Gerlach K, Väth M, Neurath MF and Weigmann B. Nuclear factor of activated $\mathrm{T}$ cells-A transcription factor family as critical regulator in lung and colon cancer. International Journal of Cancer. 2014; 134:1767-1775.

50. Clay MR, Tabor M, Owen JH, Carey TE, Bradford CR, Wolf GT, Wicha MS and Prince ME. Single-Marker Identification of Head and Neck Squamous Cell Carcinoma Cancer Stem Cells with Aldehyde Dehydrogenase. Head Neck-J Sci Spec. 2010; 32:1195-1201.

51. Ota N, Ohno J, Seno K, Taniguchi K and Ozeki S. In vitro and in vivo expression of aldehyde dehydrogenase 1 in oral squamous cell carcinoma. Int J Oncol. 2014; 44:435-442.

52. Ota N, Ohno J, Seno K, Taniguchi $\mathrm{K}$ and Ozeki S. In vitro and in vivo expression of aldehyde dehydrogenase 1 in oral squamous cell carcinoma. Int J Oncol. 2014; 44:435-442.

53. Richard V, Sebastian P, Nair MG, Nair SN, Malieckal TT, Kumar TRS and Pillai MR. Multiple drug resistant, tumorigenic stem-like cells in oral cancer. Cancer Letters. 2013; 338:300-316.

54. Davis FM, Peters AA, Grice DM, Cabot PJ, Parat MO, Roberts-Thomson SJ and Monteith GR. Non-stimulated, agonist-stimulated and store-operated $\mathrm{Ca} 2+$ influx in MDAMB-468 breast cancer cells and the effect of EGF-induced EMT on calcium entry. PLoS One. 2012; 7:e36923.

55. Lee SH, Hong HS, Liu ZX, Kim RH, Kang MK, Park NH and Shin KH. TNFalpha enhances cancer stem cell-like phenotype via Notch-Hes1 activation in oral squamous cell carcinoma cells. Biochem Biophys Res Commun. 2012; 424:58-64.

56. Liu ZH, Dai XM and Du B. Hes1: a key role in stemness, metastasis and multidrug resistance. Cancer Biol Ther. 2015; 16:353-359.

57. Chu PY, Hu FW, Yu CC, Tsai LL, Yu CH, Wu BC, Chen YW, Huang PI and Lo WL. Epithelial-mesenchymal transition transcription factor ZEB1/ZEB2 co-expression predicts poor prognosis and maintains tumor-initiating properties in head and neck cancer. Oral Oncol. 2013; 49:34-41.

58. Jordan NV, Johnson GL and Abell AN. Tracking the intermediate stages of epithelial-mesenchymal transition in epithelial stem cells and cancer. Cell Cycle. 2011; 10:28652873.
59. Yasuda K, Torigoe T, Mariya T, Asano T, Kuroda T, Matsuzaki J, Ikeda K, Yamauchi M, Emori M, Asanuma H, Hasegawa T, Saito T, Hirohashi Y and Sato N. Fibroblasts induce expression of FGF4 in ovarian cancer stem-like cells/cancer-initiating cells and upregulate their tumor initiation capacity. Lab Invest. 2014; 94:1355-1369.

60. Sansone P, Storci G, Tavolari S, Guarnieri T, Giovannini C, Taffurelli M, Ceccarelli C, Santini D, Paterini P, Marcu KB, Chieco $\mathrm{P}$ and Bonafe M. IL-6 triggers malignant features in mammospheres from human ductal breast carcinoma and normal mammary gland. J Clin Invest. 2007; 117:39884002 .

61. Todaro M, Alea MP, Di Stefano AB, Cammareri P, Vermeulen L, Iovino F, Tripodo C, Russo A, Gulotta G, Medema JP and Stassi G. Colon cancer stem cells dictate tumor growth and resist cell death by production of interleukin-4. Cell Stem Cell. 2007; 1:389-402.

62. Storci G, Sansone P, Mari S, D’Uva G, Tavolari S, Guarnieri T, Taffurelli M, Ceccarelli C, Santini D, Chieco $\mathrm{P}$, Marcu KB and Bonafe M. TNFalpha up-regulates SLUG via the NF-kappaB/HIF1alpha axis, which imparts breast cancer cells with a stem cell-like phenotype. J Cell Physiol. 2010; 225:682-691.

63. Asiedu MK, Ingle JN, Behrens MD, Radisky DC and Knutson KL. TGFbeta/TNF(alpha)-mediated epithelialmesenchymal transition generates breast cancer stem cells with a claudin-low phenotype. Cancer Res. 2011; 71:47074719.

64. Todaro M, Alea MP, Di Stefano AB, Cammareri P, Vermeulen L, Lovino F, Tripodo C, Russo A, Gulotta G, Medema JP and Stassi G. Colon cancer stem cells dictate tumor growth and resist cell death by production of interleukin-4. Cell Stem Cell. 2007; 1:389-402.

65. Baba T, Naka K, Morishita S, Komatsu N, Hirao A and Mukaida N. MIP-1alpha/CCL3-mediated maintenance of leukemia-initiating cells in the initiation process of chronic myeloid leukemia. J Exp Med. 2013; 210:2661-2673.

66. Di Stefano AB, Iovino F, Lombardo Y, Eterno V, Hoger T, Dieli F, Stassi G and Todaro M. Survivin Is Regulated by Interleukin-4 in Colon Cancer Stem Cells. Journal of Cellular Physiology. 2010; 225:555-561.

67. Burke TF, Casolaro V and Georas SN. Characterization of P5, a novel NFAT/AP-1 site in the human IL-4 promoter. Biochem Biophys Res Commun. 2000; 270:1016-1023.

68. Macian F, Lopez-Rodriguez C and Rao A. Partners in transcription: NFAT and AP-1. Oncogene. 2001; 20:24762489.

69. Buchholz M, Schatz A, Wagner M, Michl P, Linhart T, Adler G, Gress TM and Ellenrieder V. Overexpression of c-myc in pancreatic cancer caused by ectopic activation of NFATc1 and the Ca2+/calcineurin signaling pathway. EMBO J. 2006; 25:3714-3724.

70. Velupillai P, Sung CK, Tian Y, Dahl J, Carroll J, Bronson $\mathrm{R}$ and Benjamin T. Polyoma virus-induced osteosarcomas 
in inbred strains of mice: host determinants of metastasis. PLoS Pathog. 2010; 6:e1000733.

71. Liu JF, Zhao SH and Wu SS. Depleting NFAT1 expression inhibits the ability of invasion and migration of human lung cancer cells. Cancer Cell Int. 2013; 13:41.

72. Chen ZL, Zhao SH, Wang Z, Qiu B, Li BZ, Zhou F, Tan $\mathrm{XG}$ and $\mathrm{He}$ J. Expression and unique functions of four nuclear factor of activated $\mathrm{T}$ cells isoforms in non-small cell lung cancer. Chin J Cancer. 2011; 30:62-68.

73. Zhao W, Wang L, Han H, Jin K, Lin N, Guo T, Chen Y, Cheng H, Lu F, Fang W, Wang Y, Xing B and Zhang Z. $1 \mathrm{~B} 50-1$, a mAb raised against recurrent tumor cells, targets liver tumor-initiating cells by binding to the calcium channel alpha2delta1 subunit. Cancer Cell. 2013; 23:541556.

74. Sun J, Lu F, He H, Shen J, Messina J, Mathew R, Wang D, Sarnaik AA, Chang WC, Kim M, Cheng H and Yang S. STIM1- and Orail-mediated $\mathrm{Ca}(2+)$ oscillation orchestrates invadopodium formation and melanoma invasion. J Cell Biol. 2014; 207:535-548.

75. Park NH, Min BM, Li SL, Huang MZ, Cherick HM and Doniger J. Immortalization of Normal Human Oral Keratinocytes with Type 16 Human Papillomavirus. Carcinogenesis. 1991; 12:1627-1631.

76. Castilho RM, Squarize CH, Leelahavanichkul K, Zheng Y, Bugge $\mathrm{T}$ and Gutkind JS. Rac1 is required for epithelial stem cell function during dermal and oral mucosal wound healing but not for tissue homeostasis in mice. PLoS One. 2010; 5:e10503.

77. Dickson MA, Hahn WC, Ino Y, Ronfard V, Wu JY, Weinberg RA, Louis DN, Li FP and Rheinwald JG. Human keratinocytes that express hTERT and also bypass a p16(INK4a)-enforced mechanism that limits life span become immortal yet retain normal growth and differentiation characteristics. Molecular and Cellular Biology. 2000; 20:1436-1447.
78. Min BM, Baek JH, Shin KH, Gujuluva CN, Cherrick HM and Park NH. Inactivation of the P53 Gene by Either Mutation or Hpv Infection Is Extremely Frequent in Human Oral Squamous-Cell Carcinoma Cell-Lines. Oral OncologyEuropean Journal of Cancer Part B. 1994; 30B:338-345.

79. Lee EJ, Kim J, Lee SA, Kim EJ, Chun YC, Ryu MH and Yook JI. Characterization of newly established oral cancer cell lines derived from six squamous cell carcinoma and two mucoepidermoid carcinoma cells. Exp Mol Med. 2005; 37:379-390.

80. Lin CJ, Grandis JR, Carey TE, Gollin SM, Whiteside TL, Koch WM, Ferris RL and Lai SY. Head and neck squamous cell carcinoma cell lines: Established models and rationale for selection. Head Neck-J Sci Spec. 2007; 29:163-188.

81. Shin KH, Kim RH, Yu B, Kang MK, Elashoff D, Christensen R, Pucar A and Park NH. Expression and mutation analysis of heterogeneous nuclear ribonucleoprotein $\mathrm{G}$ in human oral cancer. Oral Oncol. 2011; 47:1011-1016.

82. Kim RH, Lieberman MB, Lee R, Shin KH, Mehrazarin S, Oh JE, Park NH and Kang MK. Bmi-1 extends the life span of normal human oral keratinocytes by inhibiting the TGFbeta signaling. Experimental cell research. 2010; 316:26002608.

83. Shin KH, Kim RH, Kim RH, Kang MK and Park NH. hnRNP G elicits tumor-suppressive activity in part by upregulating the expression of Txnip. Biochem Biophys Res Commun. 2008; 372:880-885.

84. Kim KD, Srikanth S, Yee MK, Mock DC, Lawson GW and Gwack Y. ORAI1 deficiency impairs activated T cell death and enhances T cell survival. Journal of immunology. 2011; 187:3620-3630. 